\title{
Sexuality, Education and Support for People with Intellectual Disabilities: A Systematic Review of the Attitudes of Support Staff and Relatives
}

\author{
Wouter de Wit ${ }^{1,2}$ - Wietske M. W. J. van Oorsouw ${ }^{1}$ (D) Petri J. C. M. Embregts ${ }^{1}$ (i)
}

Accepted: 19 December 2021 / Published online: 26 February 2022

(c) The Author(s) 2022

\begin{abstract}
Support staff and relatives are uncertain about multiple aspects of the sexuality of people with intellectual disabilities. Given that their attitudes embody positive and negative views, they can respectively support and restrict free sexual expression among people with intellectual disabilities and their potential for (intimate) relationships. A qualitative systematic literature review was conducted on the attitudes of support staff and relatives toward the sexuality of people with intellectual disabilities. A systematic search strategy was deployed across seven databases. The identified articles were screened on predetermined inclusion and exclusion criteria, and assessed on quality, which resulted in 31 included studies. A metasynthesis of these studies resulted in two major themes emerging, namely (a) attitudes toward the sexuality of people with intellectual disabilities, and (b) attitudes toward the sex education and support. Themes represented both positive and restrictive attitudes among support staff and relatives. The findings suggest that despite a general acceptance of the sexual rights of people with intellectual disabilities, certain forms of sexuality were approached more cautiously. Moreover, the sexual needs of some subgroups of people with intellectual disabilities received scarce attention. Those support staff and relatives holding rather restrictive attitudes appear to emphasize sexual risks. Finally, support staff and relatives stressed the importance of providing sex education and support for people with intellectual disabilities, while, simultaneously, expressing insecurity over the subject. The findings can help to improve the support provided to support staff and relatives to promote sexual health among people with intellectual disabilities.
\end{abstract}

Keywords Intellectual disabilities $\cdot$ Support staff $\cdot$ Relatives $\cdot$ Sexuality $\cdot$ Attitudes $\cdot$ Sex education . The Netherlands

Wouter de Wit

W.deWit@tilburguniversity.edu

1 Tranzo, Tilburg School of Social and Behavioral Sciences, Tilburg University, Postbus 90153, 5000 LE Tilburg, The Netherlands

2 Zuidwester, Middelharnis, The Netherlands 


\section{Introduction}

The sexuality of people with intellectual disabilities has been the subject of scientific research for several decades now. Up until the early 1970s, the sexuality of people with intellectual disabilities was largely denied, by, for example, labelling people with intellectual disabilities as being asexual or as having a child-like sexuality [1,2]. Acknowledgement and acceptance toward the sexual rights of people with intellectual disabilities began to increase over the course of the normalization movement [3], and, culminated in the Declaration of Sexual Rights in 2014 [4]. Notwithstanding such notable shifts, research exploring the sexuality of people with intellectual disabilities over the last two decades has predominantly focused on barriers, risks, and prejudice $[2,5,6]$. Today, despite the increased acceptance of equal rights, neither the ability to exercise free sexual expression nor the possibility to engage in (intimate) relationships are self-evident for people with intellectual disabilities $[5,7,8]$. It is well-established that engaging in sexual expression and relationships is integral to developing a healthy and positive sexuality [9]. This includes, among other things, the ability to recognize and freely choose how to express one's individual sexual needs, desires, identities, and intimacy, alongside the social competencies needed to express one's sexuality safely and appropriately, free from coercion, disease, and abuse [10-12]. However, we are not yet at the point where positive sexual health forms a key component of the support provided to people with intellectual disabilities.

In order to freely express their sexuality and engage in relationships, people with intellectual disabilities are dependent on the support and education provided by support staff and relatives $[7,13]$. The impact of support staff and relatives' attitudes appears to be significant [14-17]. Attitudes represent the degree to which we either like or dislike a certain attitudinal subject, such as sexuality [18], and subsequently, impact upon our willingness to provide support and education on that subject $[2,19,20]$. In fact, the attitudes of support staff and relatives have been found to have a greater influence over people with intellectual disabilities' freedom of sexual expression than their own abilities and attitudes [20, 21].

Given that attitudes encompass negative and positive views, they can result in both restrictive and facilitative forms of support and education [22]. Restrictive attitudes from support staff and relatives have been associated with a number of restrictions regarding the sexual expression of people with intellectual disabilities, including: (involuntary) sterilization, medication, imprisonment, obstructing the development and implementation of competency-enhancing supportive methods, and prohibition of sex education [3, 19, 23-25]. According to Servais [2], relatives in particular ignore the sexual needs of people with intellectual disabilities. Conversely, there are some nascent signs that supportive attitudes from support staff and relatives helps to promote both free sexual expression and relationship-building among people with intellectual disabilities [26]. Within extant developmental psychological literature on adolescents, these connections are being investigated more extensively [9, 27]. For example, supportive parenting has been associated with adolescents avoiding sexual risk behavior and withstanding peer pressure to engage in sexual activity $[9,28,29]$. Furthermore, research has shown that providing sex-education programs grounded in an ethos of sex-positivity and framed around sexual pleasure appeared to enhance the motivation to participate in education and generalize the acquired knowledge to their everyday lives [22].

Various scholars have highlighted the uncertainty that many support staff and relatives have concerning their roles and responsibilities toward the sexuality of people with intellectual disabilities $[5,7,30,31]$. Therefore, an up-to-date overview of extant research on 
the attitudes of support staff and relatives concerning the sexuality of people with intellectual disabilities, considering both supportive and restrictive attitudes. This qualitative systematic literature review was conducted in accordance with PRISMA guidelines [32].

\section{Method}

\section{Search Strategy}

The search strategy was conducted in accordance with the Exhaustive Search Method (ESM) [33], as well as with the support of an information specialist. In order to provide an adequate representation of all the relevant literature on this topic, seven specialist academic databases were searched, namely: Embase, Medline Ovid, Web of Science, Cochrane Central, PsychINFO Ovid, CINAHL EBSCOhost, and Google Scholar. In concordance with ESM, a systematic search was carried out based on free text search words, adding relevant thesaurus terms when needed. We engaged in a process of trial runs and comparison of the results in order to optimize the results.

In order to help structure the search terms, the PICO-approach was used to specify the search terms for population, intervention/exposure, comparison, and outcome [32]. Please refer to Table 1 to see an example of our search within the Embase database. The different components of the PICO-approach were formulated as follows: (1) Population: support staff and relatives of people with intellectual disabilities, (2) Exposure: sexuality of adults with ID, (3) Control: not applicable, and (4) Outcome: attitudes. Support staff refers to any healthcare personnel that is providing direct care to people with intellectual disabilities, while relatives refers to any persons who have a first-degree relative with an intellectual disability (i.e., parents, and siblings). Regarding interventions, we used relevant search terms that applied to the sexuality of people with intellectual disabilities, which were based on the dimensions of the WHO working definition [12], including sex, gender identities and roles, sexual orientation, eroticism, pleasure, intimacy, and reproduction. The outcome consisted of attitudes, which includes cognitions, affects, and behavioral intentions [34]. The search focused on original, English language peer-reviewed studies, which were published between January 1997 and June 2017. An update of the search was conducted in June 2020.

For each component of PICO, a list of search terms was formulated. These search terms were selected based on MeSH-terms and keywords. The latter were determined based on synonyms, subcategories, and the use of a thesaurus. All the search terms included singular, plural, and verbal forms. In order to build the search string, Boolean operators were used. This involved either combining the components using "AND", or separating synonyms using "OR". When relevant, the exclusion criteria were utilized by using "NOT".

\section{Study Selection}

See Fig. 1 for a flow diagram of the selection process. In accordance with the PRISMA Statement, the study selection comprised four sequential phases: (1) identification, (2) screening, (3) eligibility, and (4) selection [35]. In the identification phase, the eligible studies were identified by applying the predetermined search string. This initial search resulted in 7390 studies. All duplicates and non-original studies (i.e., dissertations and 
Table 1 Search terms and synonyms medline ovid

Final search strategy

(exp Intellectual Disability/OR Mentally Disabled Persons/OR Learning Disorders/OR Developmental Disabilities/ OR (((intell* OR mental* OR cognit* OR neurocognit*) ADJ3 (impair* OR disab* OR handicap* OR deficien* OR retard* OR deficit* OR disabilit* OR limitation*)) OR idioc* OR (retard* NOT (retard* ADJ6 (intrauterine* OR intra-uterine* OR iugr OR growth)) ) OR (down ADJ2 syndrome*) OR development* disab* OR development* delay* OR development* disorder* OR learning* disab*).ab,ti.)

AND (attitude/OR Patient Preference/OR patient satisfaction/OR Attitude of Health Personnel/OR Social Norms/ OR social stigma/OR prejudice/OR taboo/ OR (attitude* OR acceptance* OR stigma OR prejudice* OR taboo* OR (social ADJ3 (value* OR discriminat*)) OR judgement* OR criticism* OR considerat* OR reasoning OR ((perspective* OR thought* OR thinking OR knowledge* OR affect OR affection OR emotion* OR feeling* OR like OR liking OR dislike OR disliking OR favour OR disfavour OR opinion* OR decision OR judge OR experience* OR virtue* OR reflect* OR view OR views OR impression* OR aware* OR reali* OR belief* OR instinct* OR marginali* OR neglect* OR ignor* OR supportive OR filiation*) ADJ6 (professional* OR personnel* OR staff OR provider* OR nurse* OR nursing OR worker* OR attendant* OR field-worker* OR fieldworker* OR residential-care* OR care-giver* OR caregiver* OR carer* OR patient* OR client* OR peoplewith OR famil* OR parent* OR father* OR mother* OR sibling* OR brother* OR sister* OR relatives OR first-degree-relative*))).ab,ti.)

AND (gender identity/OR exp sexuality/OR Sex Workers/OR love/OR Contraception/OR ((Abortion, Induced/ OR pregnancy/OR Reproductive Health/) NOT (Down Syndrome/OR Fetal Alcohol Spectrum Disorders/OR mass screening/OR Prenatal Diagnosis/)) OR Parturition/OR Pregnancy, Unplanned/OR Pregnancy, Unwanted/ OR Libido/OR marriage/OR Menstrual Cycle/OR Penile Erection/OR exp Contraceptive Devices/OR (sexualit* OR affectivit* OR intimate-relationship* OR transgender* OR bicurious OR bisexual* OR cross-sex* OR crossgender* OR female-to-male OR gay OR gays OR gender-variant OR intersex* OR ((gender OR sex OR sexual* OR sociosexual* OR psychosexual*) ADJ3 (change* OR dysphor* OR identit* OR reassign* OR transform* OR transition* OR minorit* OR preferen* OR identit* OR orient* OR industr* OR service* OR work OR worker* OR pleasure* OR contact* OR physical* OR reproduct* OR behav* OR protect* OR responsib* OR counsel* OR thought* OR thinking OR fantas* OR desire OR longing OR urge OR expectation* OR belief* OR attitude* OR value* OR virtue* OR norm OR normal OR conviction* OR extramarital* OR extra-marital* OR premarital* OR pre-marital* OR relation* OR interact* OR anal OR oral OR experien* OR career* OR activit* OR friendship* OR friend* OR wellbeing OR well-being OR hygien* OR satisf* OR content* OR fullfill* OR attract* OR arous* OR drive OR autonom* OR independen* OR boundar* OR body-part OR body-image OR self-image OR self-concept OR self-esteem OR consent* OR support* OR priva* OR knowledge* OR comprehen* OR understand* OR physiolog* OR anatom* OR educat* OR psychoeducat* OR right OR needs OR favour* OR abstinen* OR anxi* OR depress* OR fear)) OR marriage OR (family-life ADJ3 educat*) OR masturbat* OR blowjob OR blow-job OR cybersex* OR Genderqueer* OR GLB OR GLBQ OR GLBs OR GLBT OR GLBTQ OR Heteroflexib* OR homosexual* OR homosexuals OR intersex* OR lesbian* OR lesbigay OR LGB OR LGBQ OR LGBTQ OR LGBS OR LGBT OR male-to-female OR sex-with-men OR queer OR samegender OR same-sex OR Sexual* OR (trans ADJ (female OR male OR man OR men OR people OR person* OR woman OR women)) OR Transexual* OR Transgender* OR Transsexual* OR trans-sexual* OR transvestit* OR men-loving-men OR women-loving-women OR sex-with-women OR intercourse* OR erotic* OR autoerotic* OR promisc* OR courtship* OR dating OR libido OR two-spirit-person* OR crossdress* OR heterosexualit* OR prostit* OR hooker* OR gigolo* OR pornograph* OR porn OR escort-service* OR escortservice* OR intimac* OR intimat* OR love OR lovelife OR romance OR coitus OR penetrat* OR birth control OR contracept* OR sterilizat* OR ((abortion OR pregnan* OR reproductive health)

NOT (Down* syndrome OR Down s syndrome OR fetal alcohol OR foetal alcohol OR screening OR genetic-test* OR prenatal-test* OR prenatal-diagnos*)) OR the-pill OR condom OR family-planning OR childbirth* OR child-birth* OR labor OR labour OR ((unplanned OR unwanted) ADJ3 pregnan*) OR menstrual OR menstruat* OR erection* OR orgasm* OR (remov* ADJ3 uter*) OR castrat* OR ((intrauterin* OR intra-uterin*) ADJ3 device*)).ab,ti.)

NOT (exp dementia/OR (dement*).ab,ti.)

NOT (exp aged/ NOT (adult/OR adolescent/))

NOT (letter OR news OR comment OR editorial OR congresses OR abstracts).pt

AND english.la

Similar search strategies were used for Embase, CINAHL, Psych INFO, Web of Science, Cochrane CENTRAL, and Google Scholar, with adjustments to the search terms based on the applicable thesaurus and MeSH-terms 


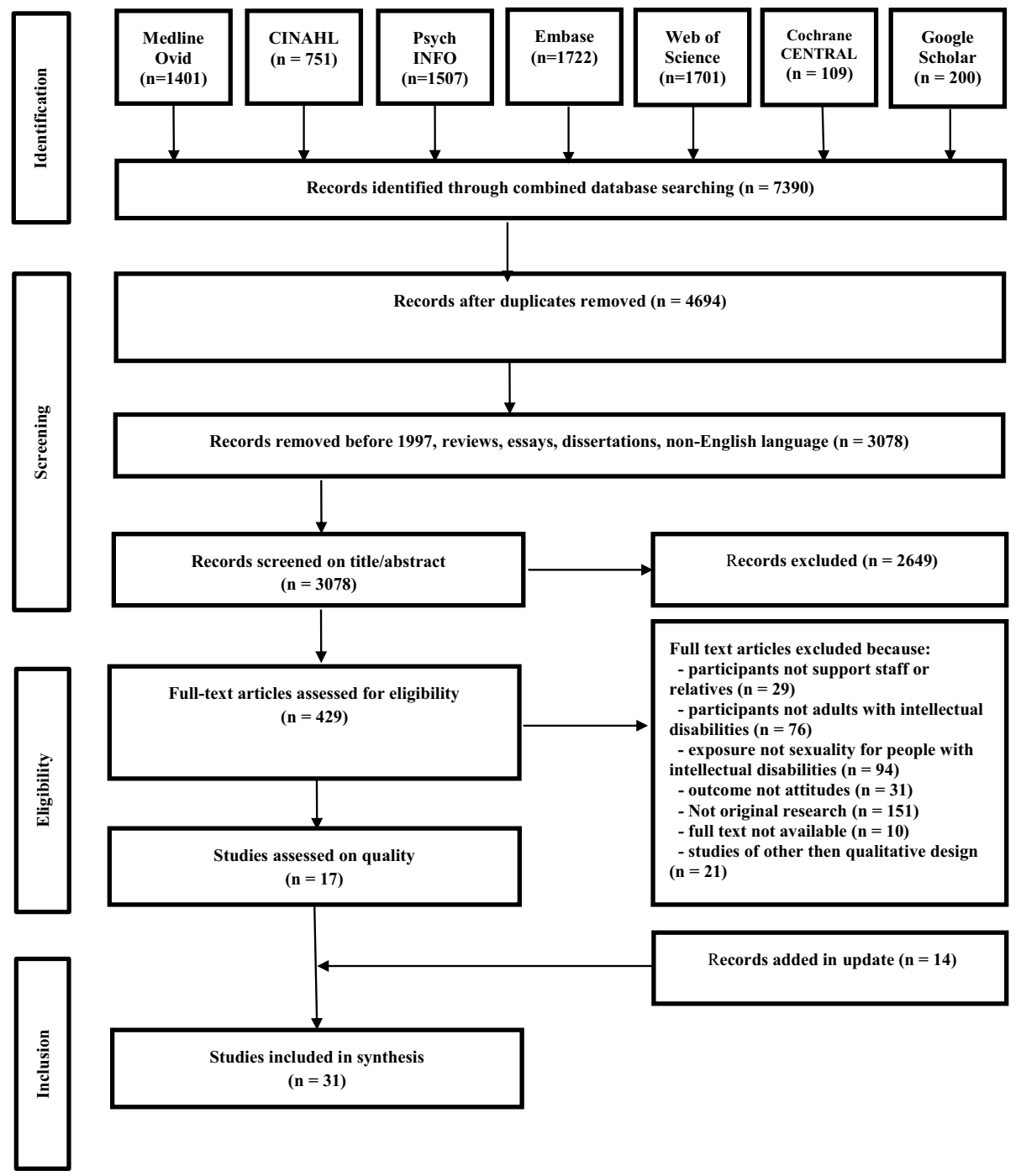

Fig. 1 Flow-chart systematic reviews

systematic reviews) were removed, resulting in 3038 studies being suitable for the next stage of the selection process.

In the screening phase, the first and second author independently screened the titles of the studies in relation to the inclusion and exclusion criteria (Table 2). Absolute agreement was assessed and calculated at a ratio of $81 \%$. All disagreements were discussed until a consensus was established. In difficult cases, the third author was consulted. The abstracts of the remaining 1499 studies were then screened independently regarding the same criteria by the first two authors. Absolute agreement was assessed, and calculated at a ratio of $73 \%$. Once again, in the event of disagreement, the abstracts were discussed at length until a consensus was reached, with the third author being 


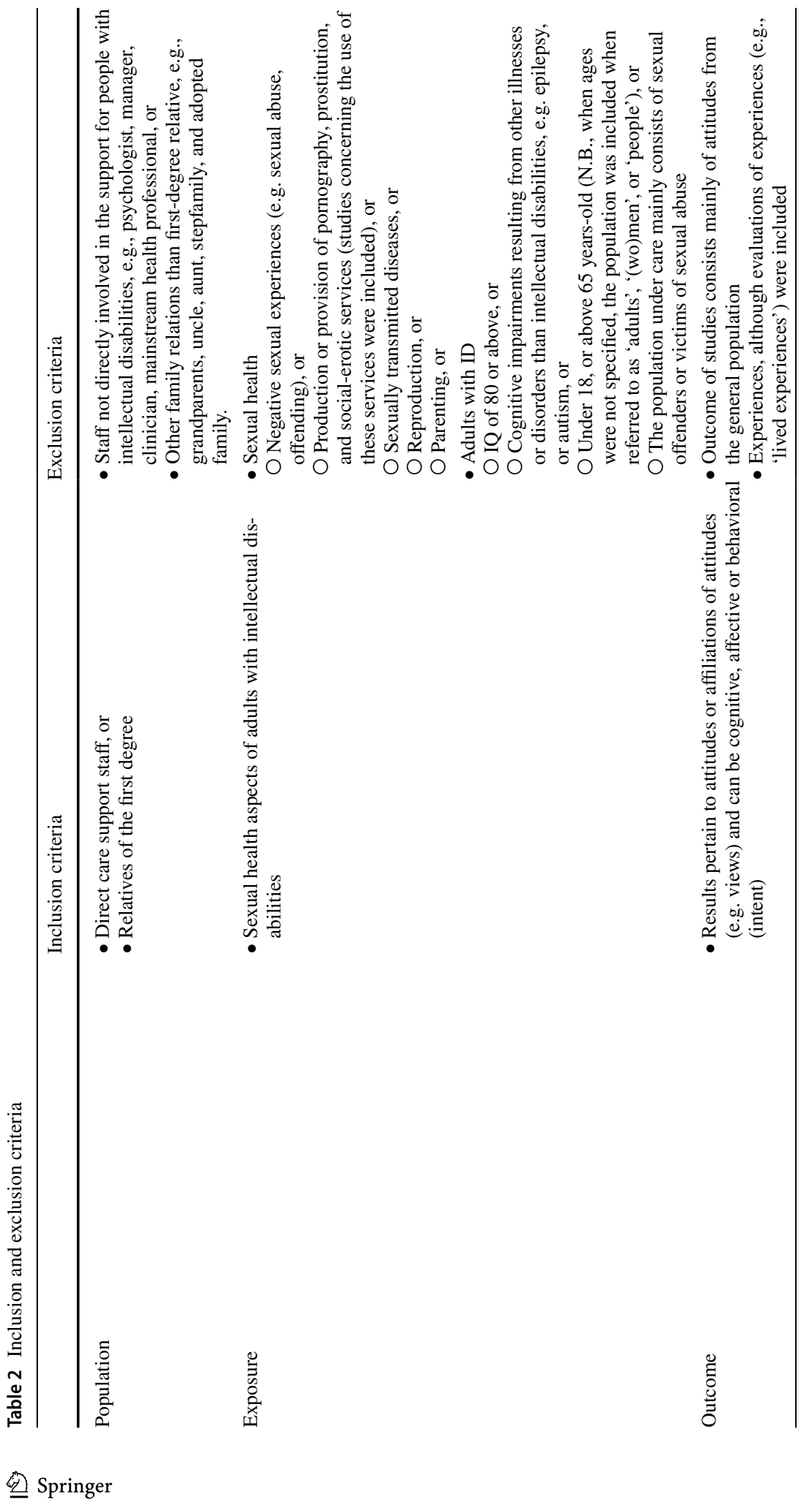




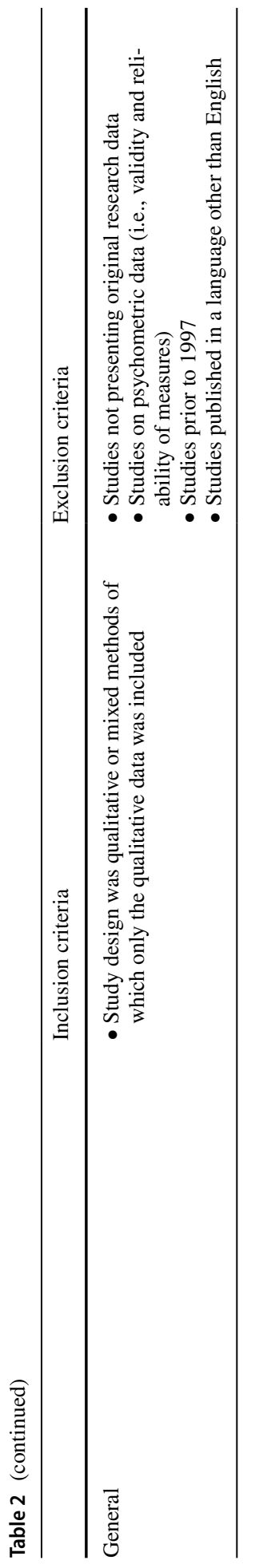


consulted in particularly complex cases. The screening phase resulted in a selection of 419 studies to subsequently be screened for eligibility.

In the eligibility phase, the full texts of the 419 studies were screened with respect to the PICO-components sequentially (i.e., population, exposure, and outcome). The first author screened the studies, and thoroughly discussed the studies with the second author until full agreement was reached. The third author was consulted in complex cases. 68 studies remained following the eligibility phase, which were subsequently critically appraised by using the Mixed Methods Appraisal Tool (MMAT version 2018) [36]. Similar to the eligibility phase, the first author appraised the studies and extensively discussed them with the second author until agreement was reached. Following the critical appraisal, no articles were excluded due to a lack of quality.

At this point, those studies that either included a population comprising people with intellectual disabilities (see De Wit et al. [26] for a review of the perspectives of people with intellectual disabilities) or were grounded in a quantitative research design were excluded. Consequently, the final selection consisted of 17 qualitative and mixed-method studies exploring the attitudes of support staff and relatives. Of the mixed-method studies, only the qualitative data was included in our review. An update of the search was conducted in June 2020. The selection followed exactly the same procedure described above. Fourteen studies were added, resulting in a final selection of 31 included studies.

\section{Data extraction and Analysis}

Data was extracted and analyzed in accordance with the metasynthesis approach described in Lachal et al. [37]. This method comprises five steps, which enable the conscientious synthesis of qualitative data. In the first step, a thorough comprehension of the included studies was sought through reading and rereading. Second, data was extracted through a careful process of line-by-line coding. The third step focuses on data synthesis. Specifically, codes with similar meanings were grouped into categories. Similarly, categories with similar meanings were grouped together and an overall category was then formulated, i.e., the subtheme. Through this procedure a hierarchical tree structure was ultimately formed, which was extensively discussed by the three authors. In the final step, the subthemes were organized into groups that conveyed similar meanings. The resulting groups were thoroughly discussed in the research group, which resulted in the formation of overarching analytical themes.

\section{Results}

\section{General}

The included studies focused on the attitudes of direct support staff $(n=15)$, relatives $(n=9)$, or both $(n=7)$, which were substantially divided into two major themes, namely: (1) attitudes towards the sexuality of people with intellectual disabilities, and (2) attitudes toward the sex education and sexuality-based support provided to people with intellectual disabilities. Please refer to Table 3 for an overview of included studies. 


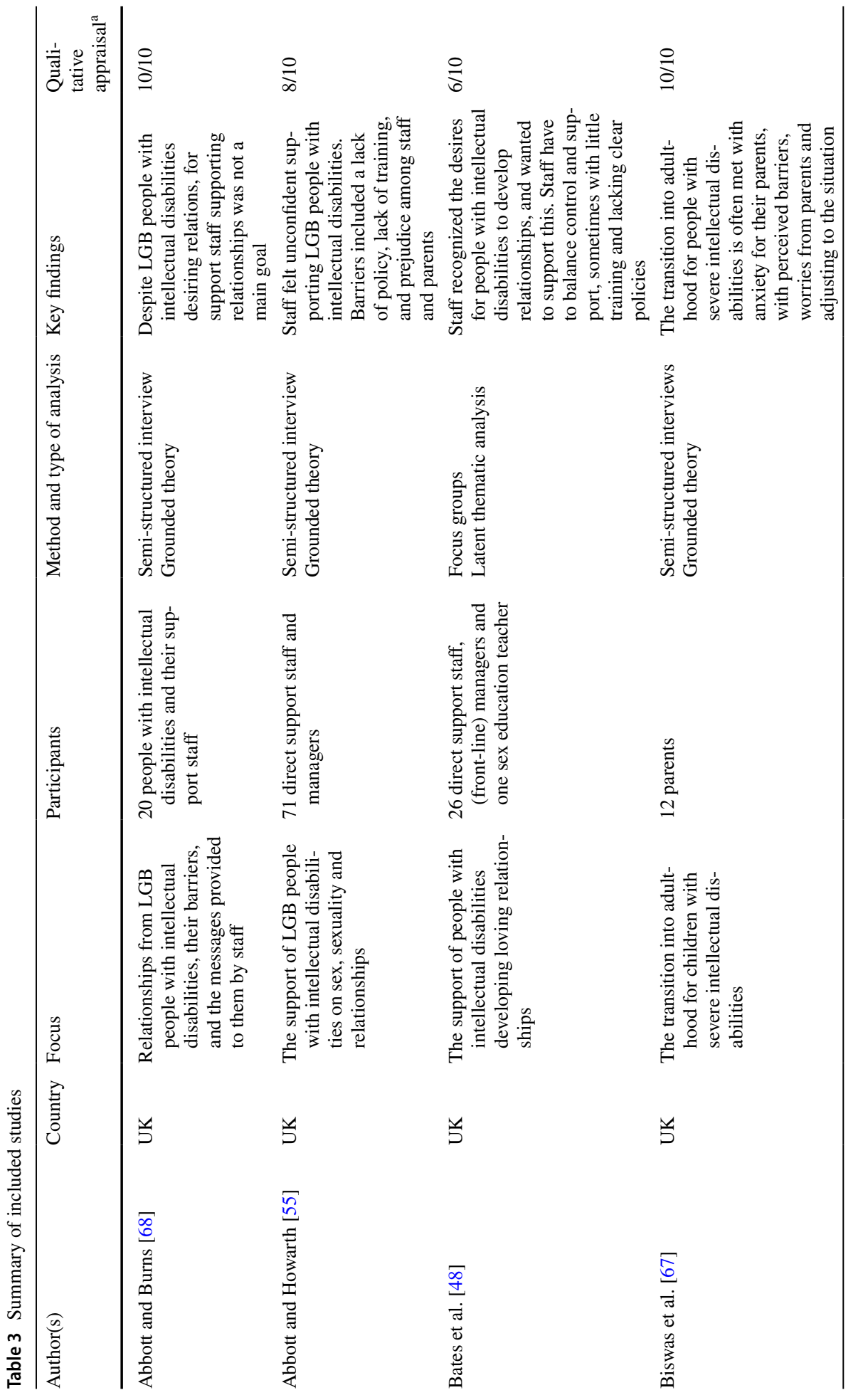




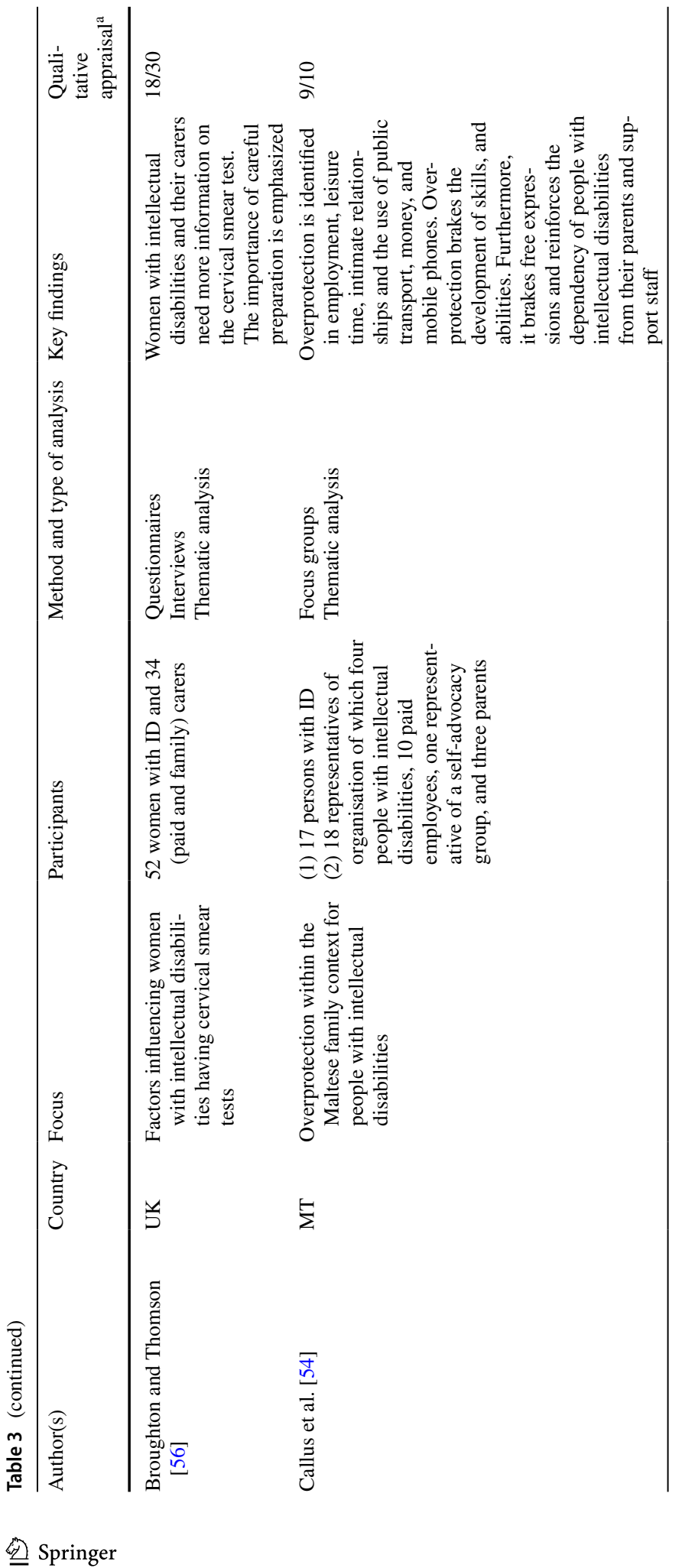




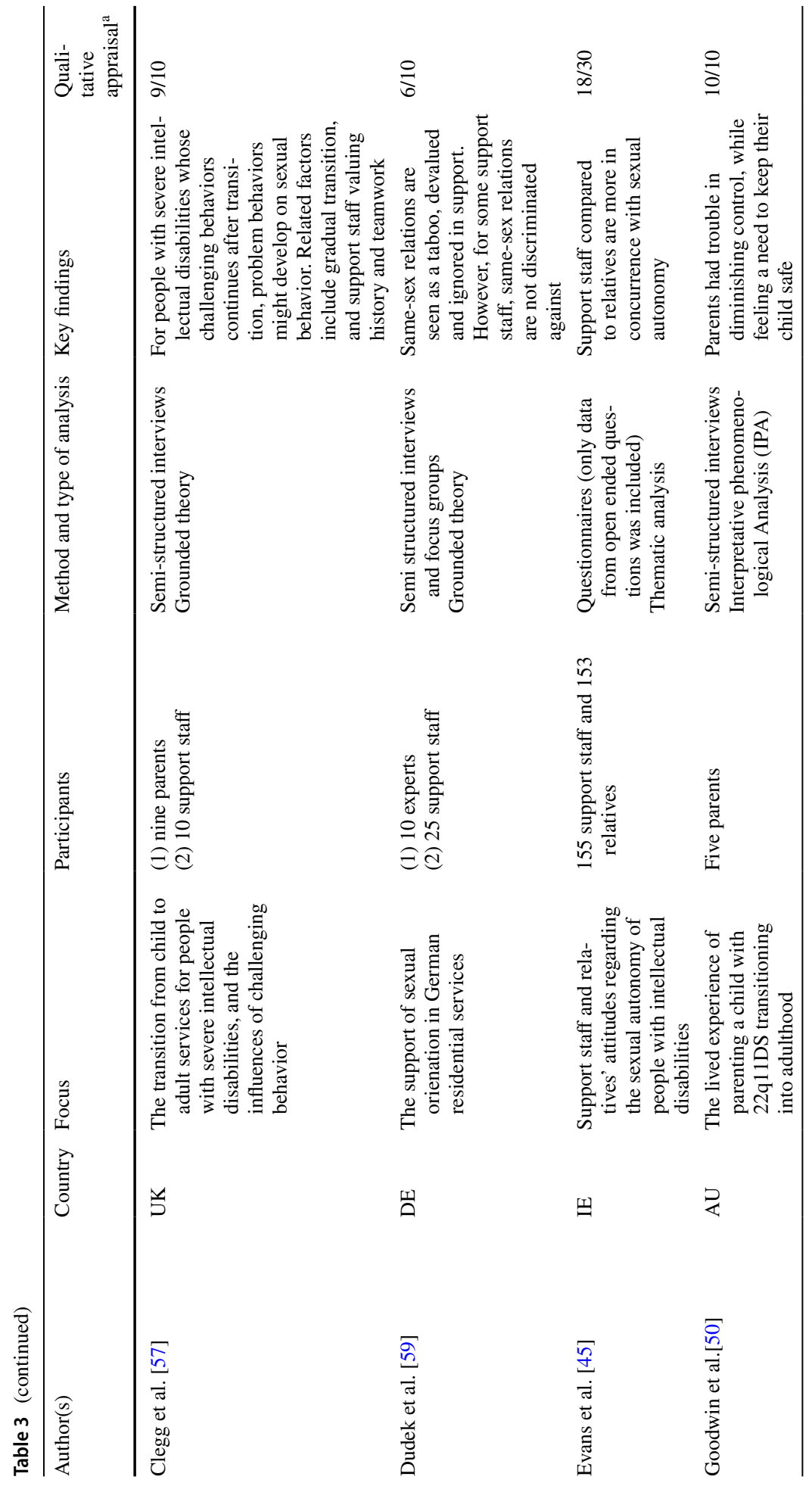




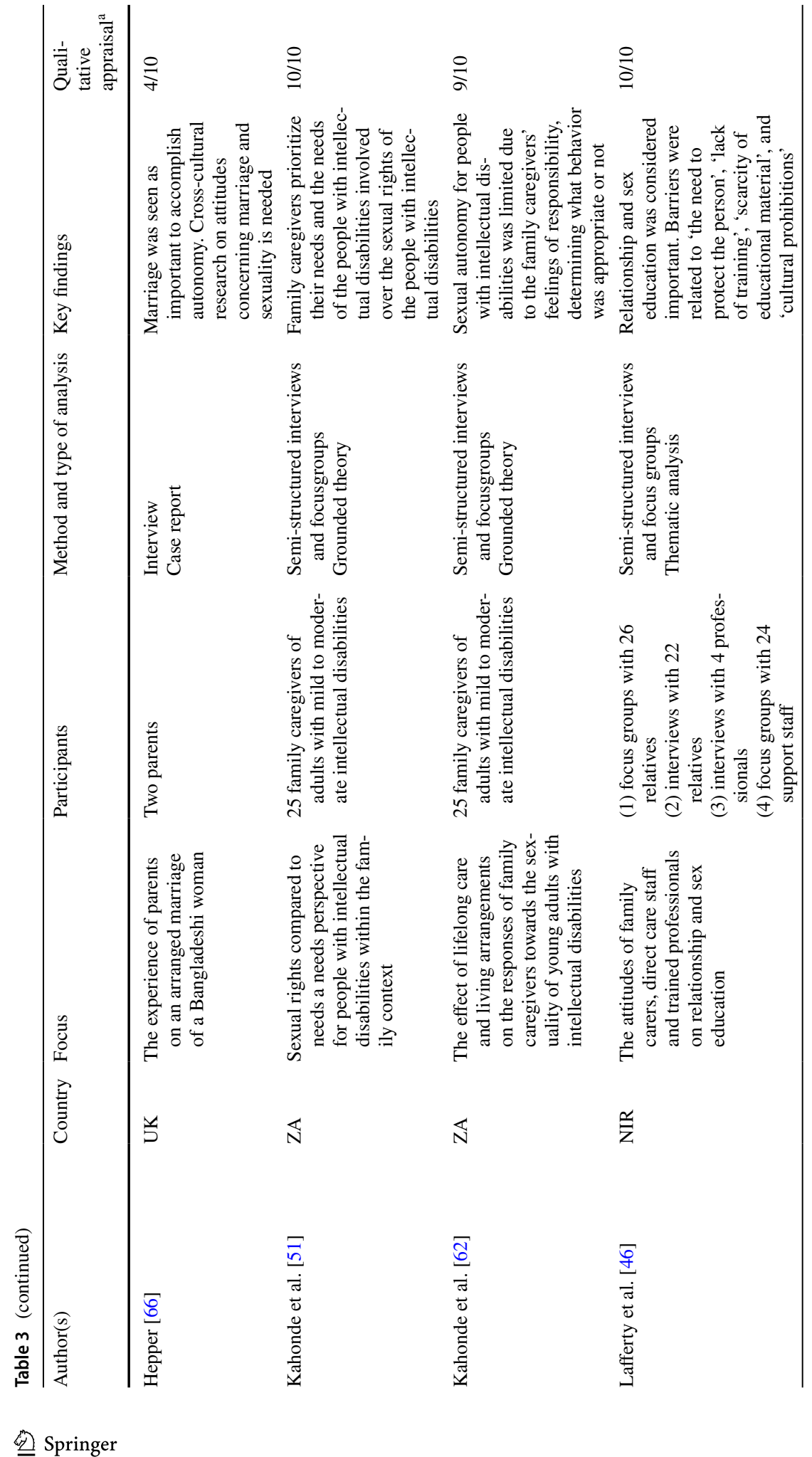




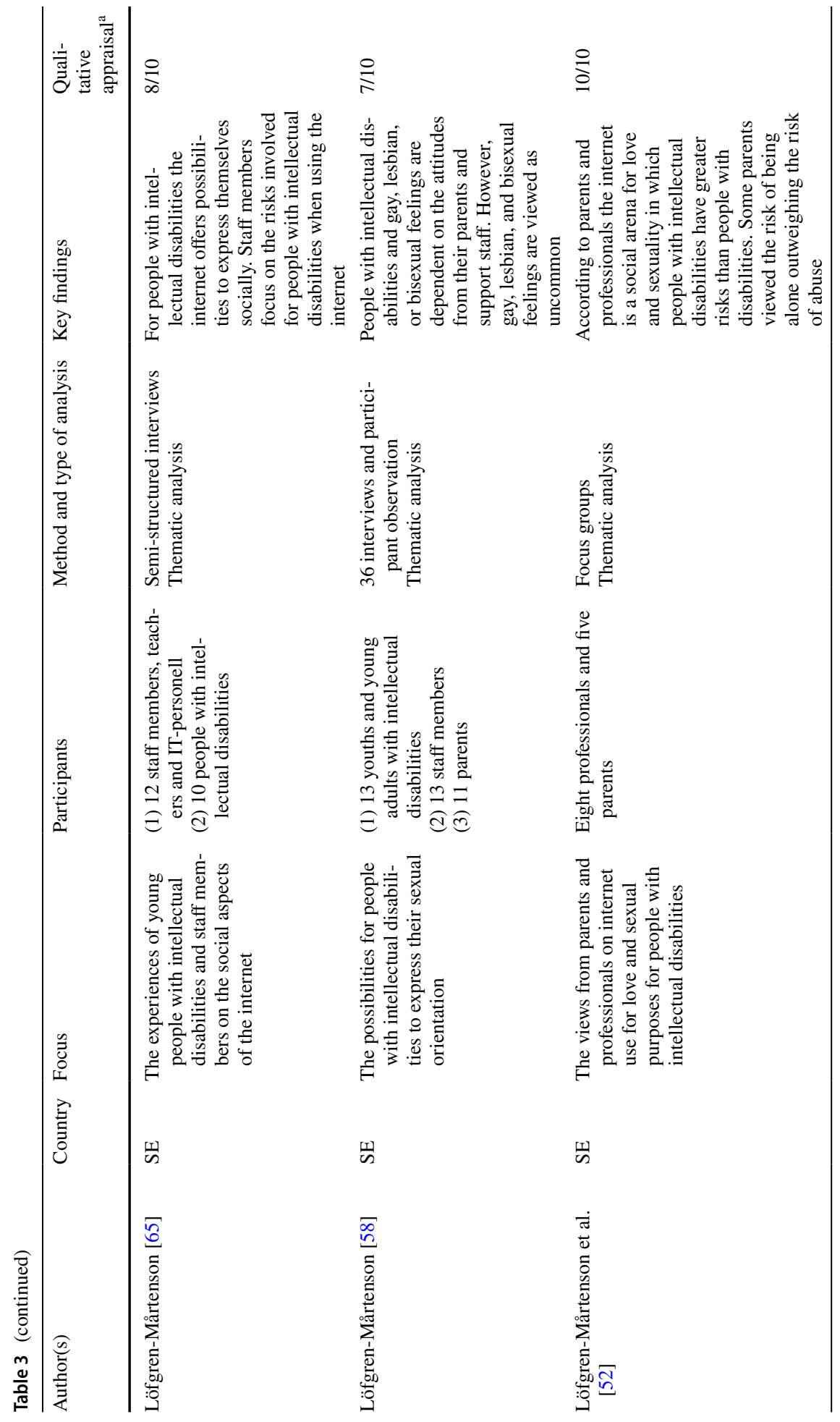




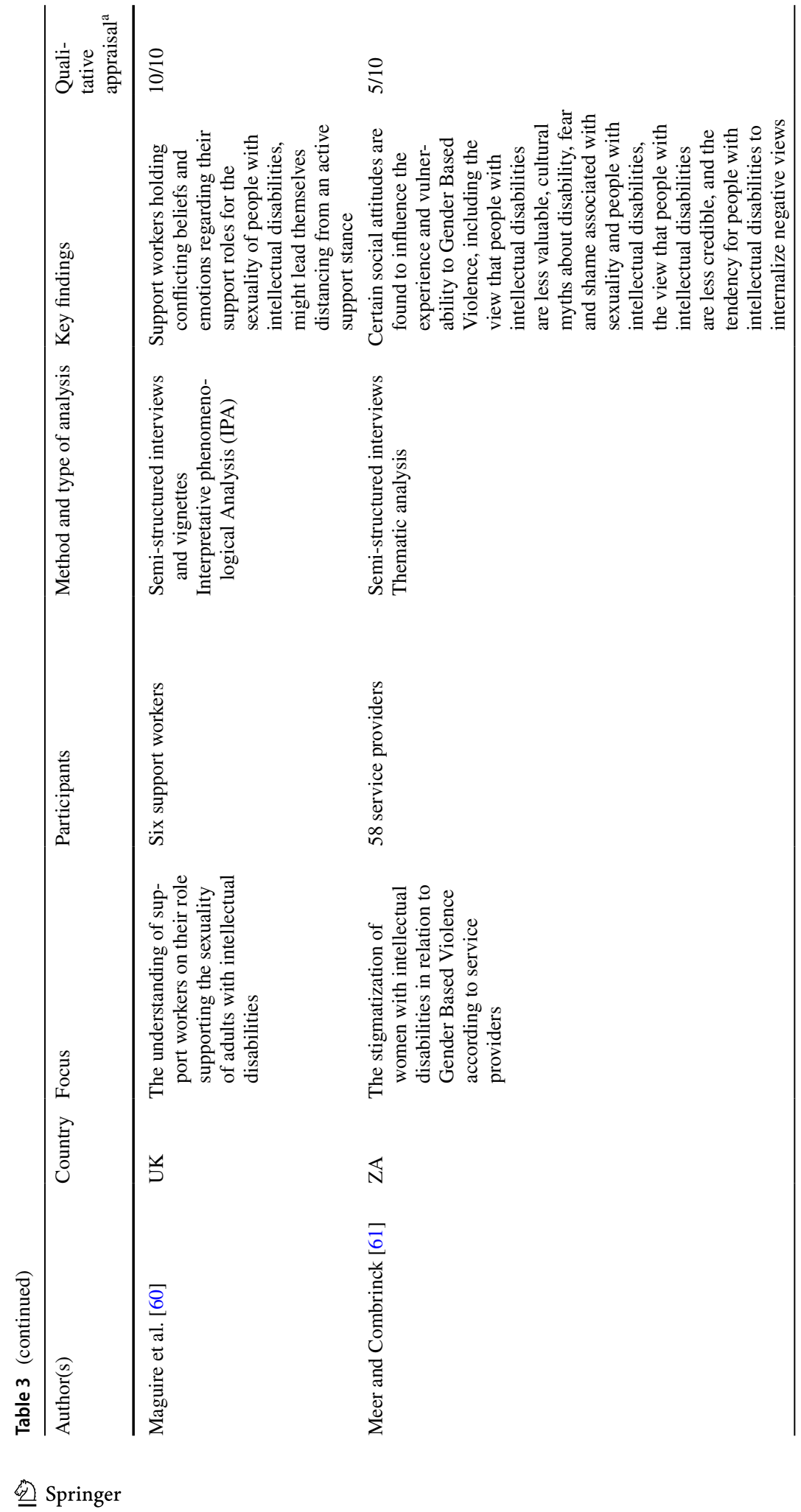




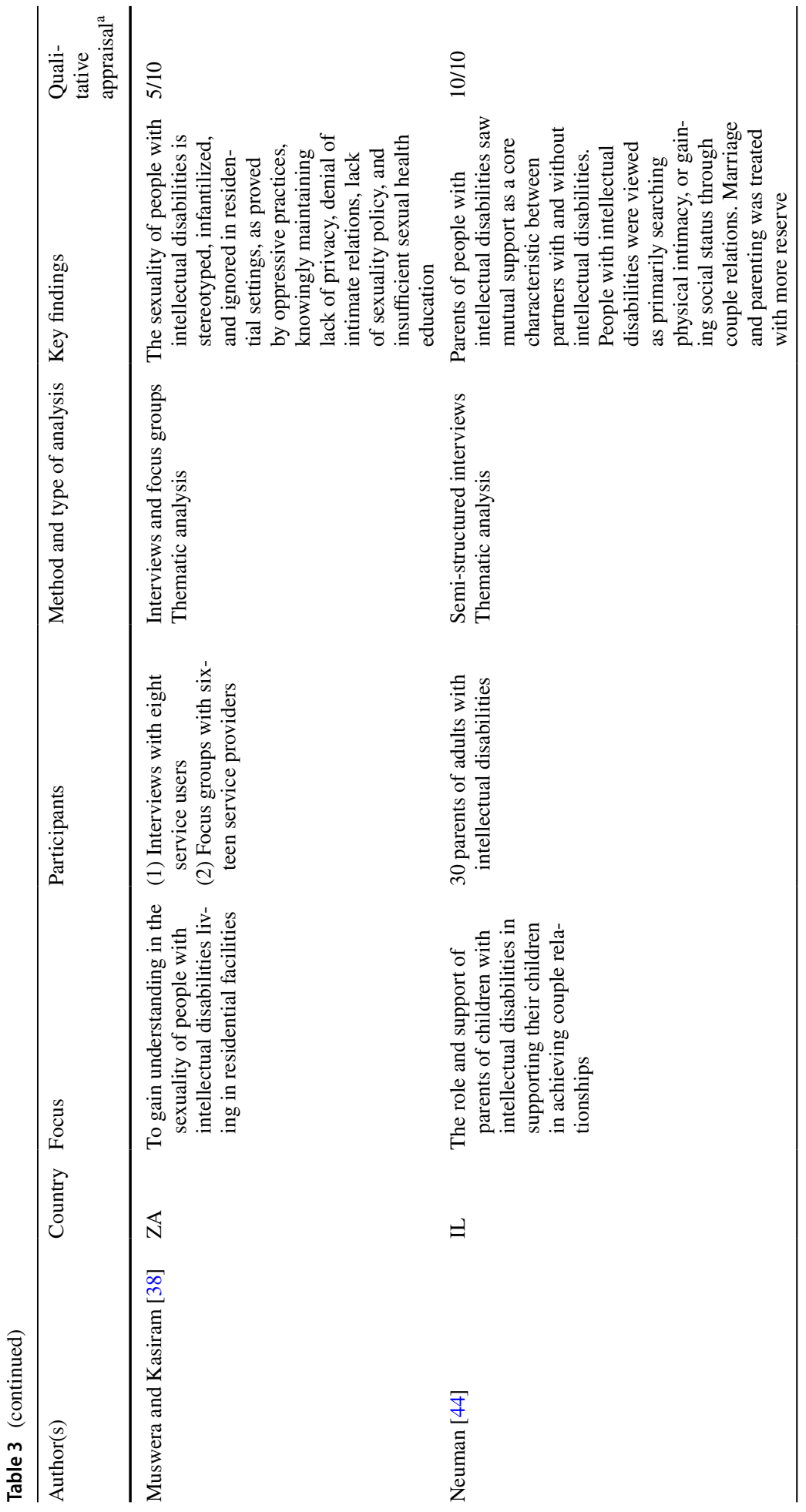




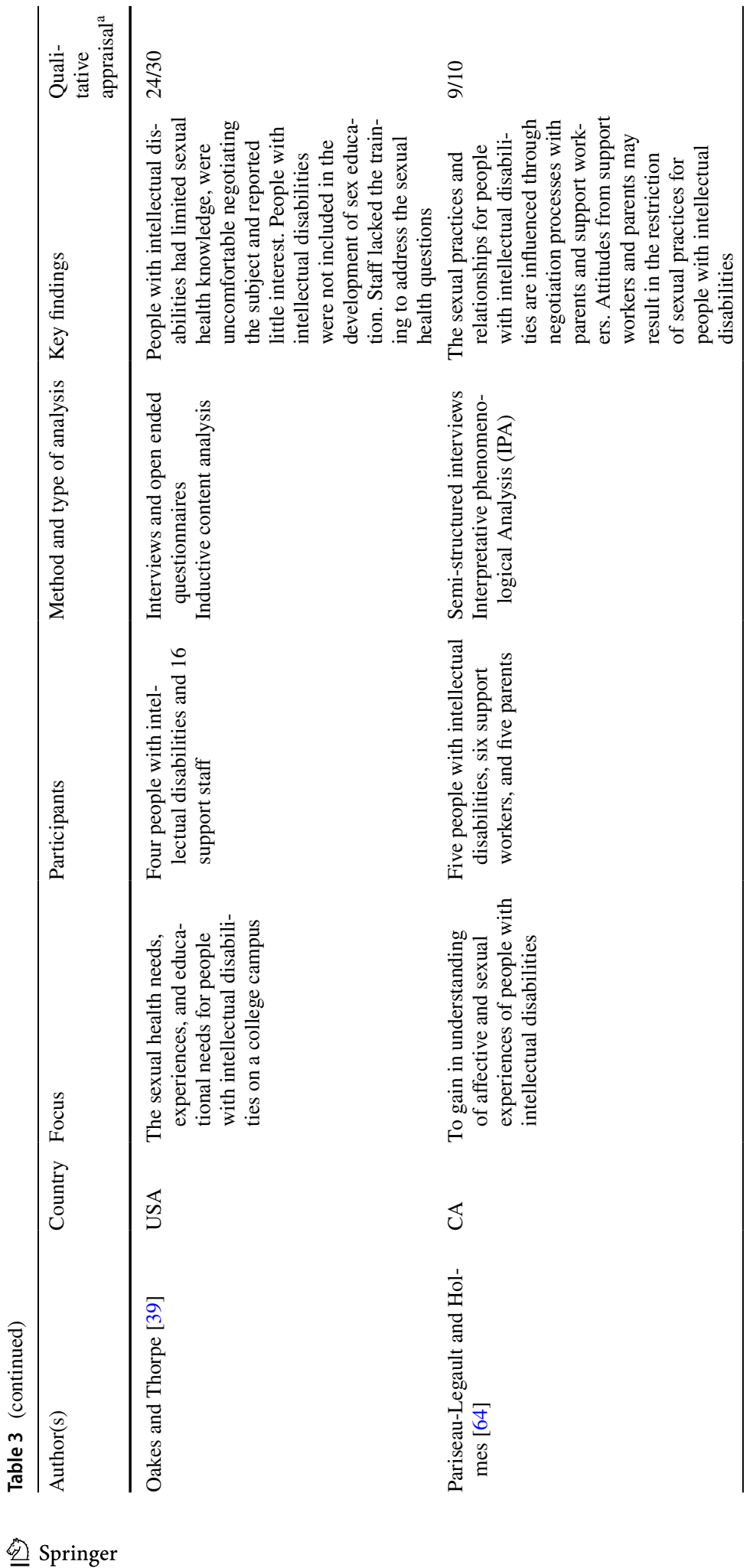




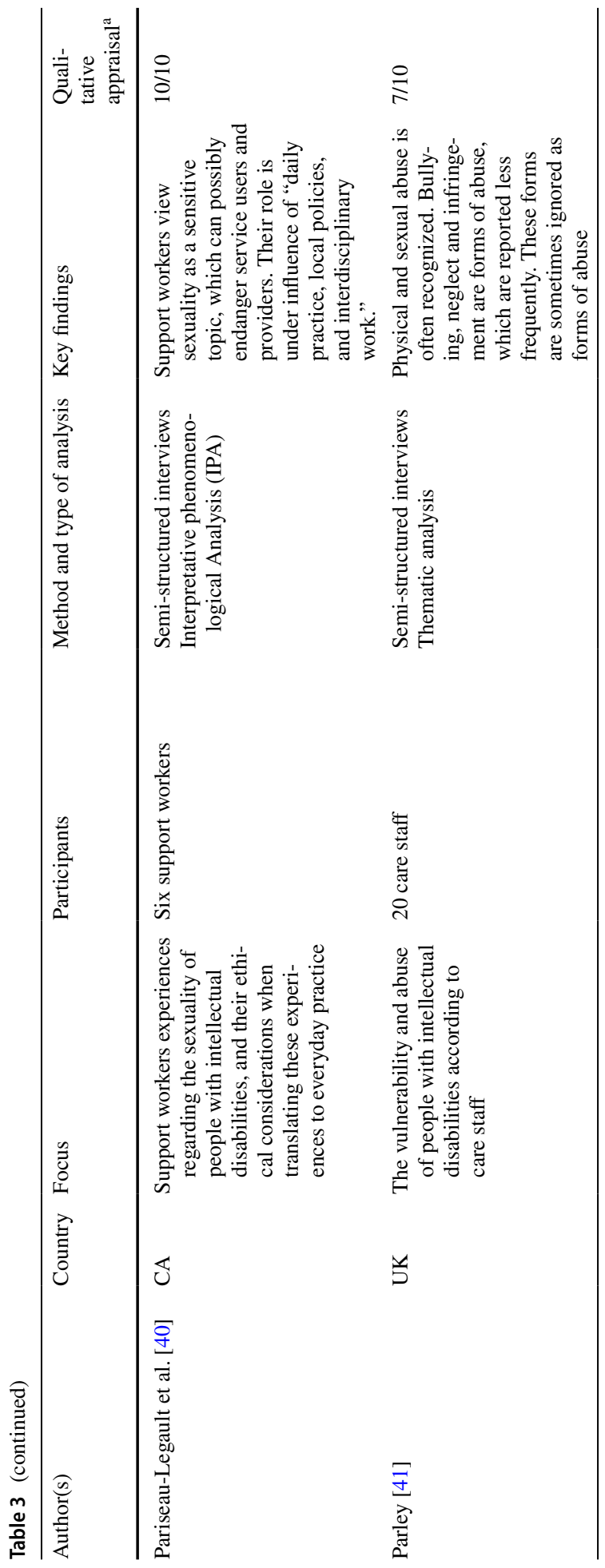




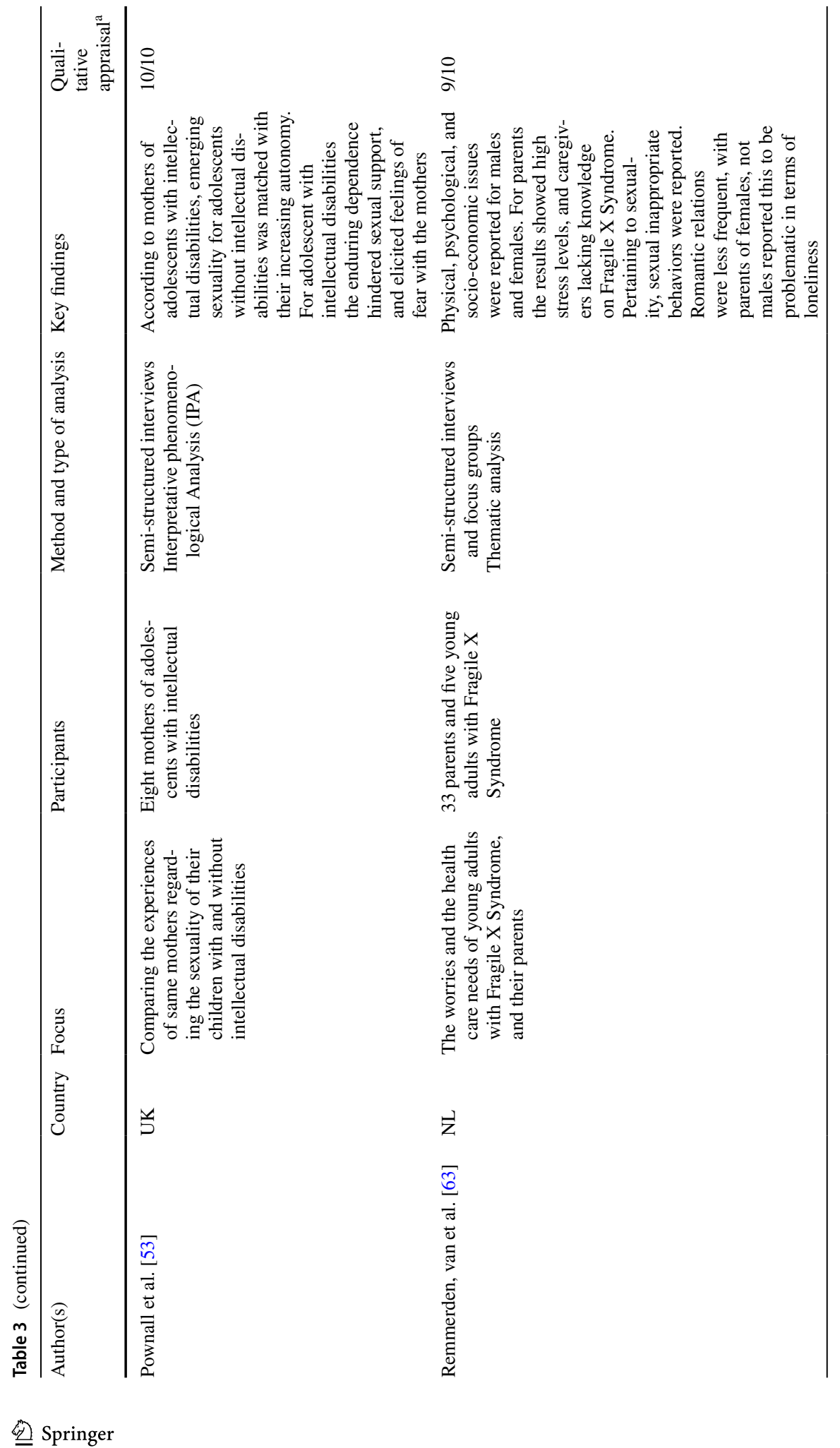




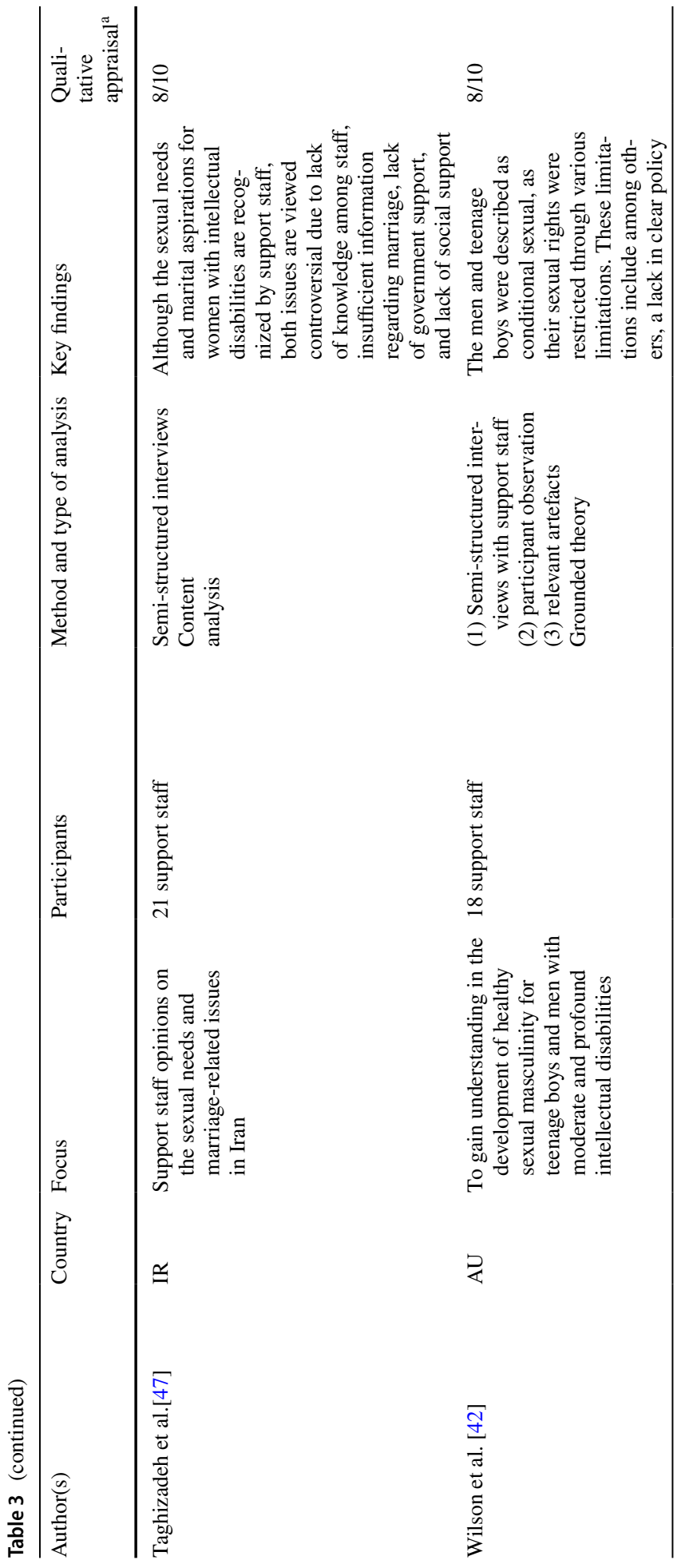




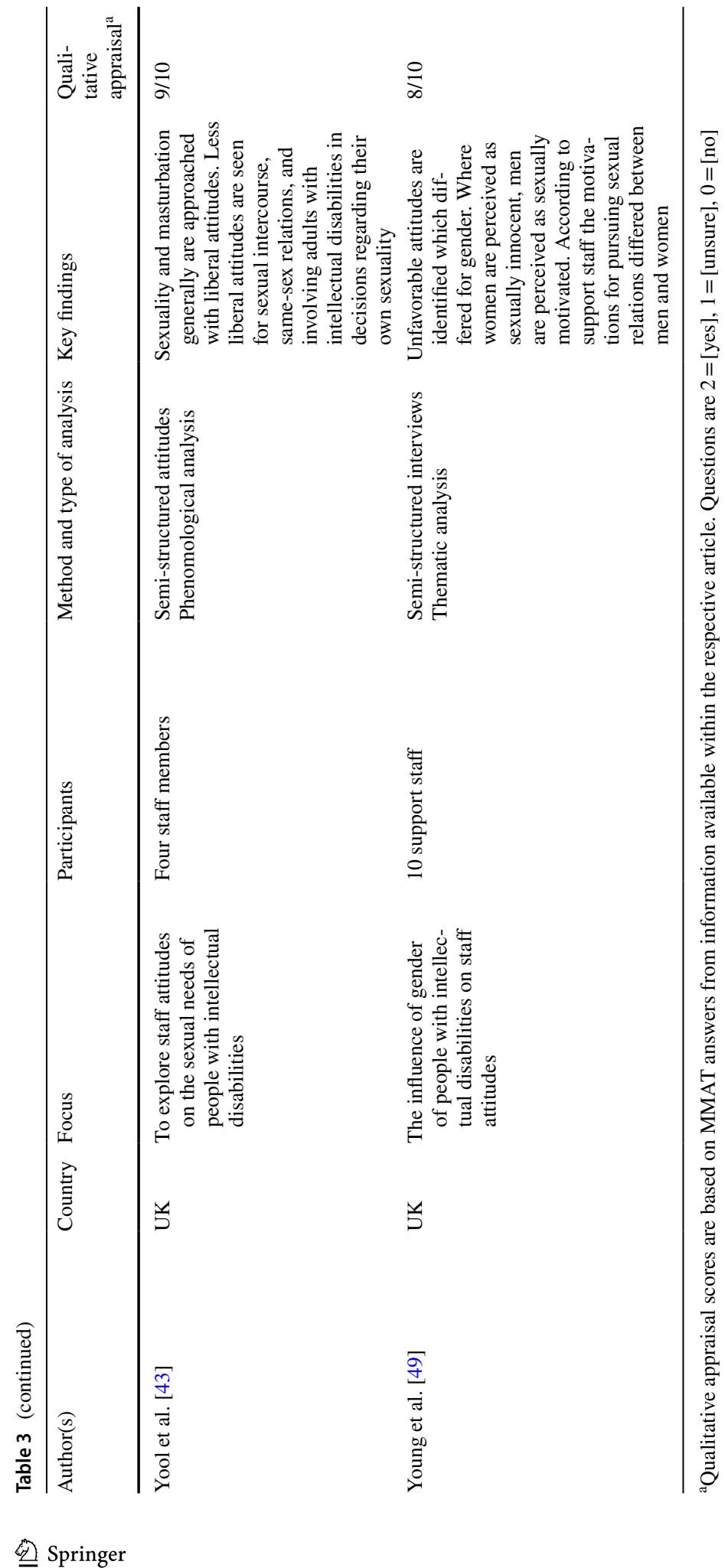




\section{Theme One: Attitudes Towards the Sexuality of People with intellectual disabilities}

The first theme consisted of five subthemes, which are explained in more detail in the following sections.

\section{Sexual Rights of People with Intellectual Disabilities}

Attitudes toward the sexual rights of people with intellectual disabilities were identified in six studies that focused on support staff [38-43], one study on relatives [44], and three studies that combined both perspectives [45-47]. Quotes in these studies primarily reflected supportive attitudes. For instance, one of the support staff mentioned, that "everybody has a right to sexuality" [43, p. 143], while a relative explained that "it is clear to me that they are allowed to have sex" [44, p. 315]. However, several support staff and relatives agreed that sexuality remained a "very taboo subject" [46, p. 38, relative].

\section{Sexual Needs and Feelings of People with Intellectual Disabilities}

Heterogeneous attitudes were expressed toward the sexual needs and feelings of people with intellectual disabilities within five studies focusing on support staff [38, 40, 42, 48, 49], five on relatives [44, 50-53], and two studies that took the perspectives of both into account $[47,54]$. On the one hand, several support staff and relatives agreed that people with intellectual disabilities have the same sexual feelings, in the words of a relative "as the rest of us" [51, p. 285; 40, 47]. On the other hand, some support staff and relatives experienced difficulties recognizing the sexual feelings of people with intellectual disabilities $[50,53,54]$.

Moreover, some support staff indicated that the presence of sexual feelings depended on clients' age, gender, and/or the severity of their disability [42, 49]. For example, staff expected older people to have less sexual needs [42], while some staff believed that men would have more sexual needs, and "the women don't really... they're not fussed that much" [49, p. 344]. Finally, the support staff indicated that a more severe intellectual disability made it more unlikely that a person would have sexual needs [42]. Although, one of the support staff mentioned, "their sexual need is not dependent on their intelligence" [47, p. 35]. Attitudes toward the potential relation between sexual feelings and clients' characteristics were not identified for relatives.42, 43, 49, 55, 56

\section{People with Intellectual Disabilities' Understanding of Sexuality}

Part of the reported attitudes of support staff [i.e., five studies; ], relatives [i.e., five studies; $44,50,51,52,53$ ], or both [i.e., three studies; 46, 57, 58] touched upon the assumed ability of people with intellectual disabilities to understand sexuality. Three topics emerged. The first topic concerned the difficulties that young people with intellectual disabilities faced in terms of understanding the physical changes associated with puberty, for example, coping with their first period $[51,53]$. With respect to adjusting to physical changes, only restrictive attitudes of relatives were found. Second, both support staff and relatives expressed that people with intellectual disabilities were lacking social skills, which, in turn, made it difficult for them to understand sexual interactions. Consequently, this could put people with intellectual disabilities at risk of sexual abuse, as either a perpetrator or a victim [42, 
49, 51, 53, 57]. As one relative explained about potential perpetrating: "if he takes a fancy to them he's - you could perhaps call him a stalker - he makes their lives a misery" [57, p. 160]. Regarding the risk of victimization, one of the support staff mentioned: "sometimes the females entice men but not really noticing what they are doing ... they just want a cuddle and haven't got an appreciation of what it might mean" [49, p. 344]. Finally, both support staff and relatives believed that having an intellectual disability made it more difficult to understand and accept sexual identity [58]. Some support staff and relatives added that, although people with intellectual disabilities could well be aware of the concept of sexual orientation, they would not understand what this entails [46, 55]. Furthermore, according to Young et al. [49], some support staff considered a gay identity to be inappropriate for people with intellectual disabilities: “... oh my god, its two men” (p. 345). Other support staff stated that whatever a person's sexual orientation was, “... we should give the same support" [55, p. 119].

\section{Sexual Behavior of People with Intellectual Disabilities}

Support staff and relatives were quoted with respect to their attitudes toward the sexual behavior of people with intellectual disabilities in 10 [38, 39, 42, 43, 48, 49, 55, 59-61] and six studies [50-53, 62, 63], respectively. Two studies drew upon the perceptions of both groups $[47,64]$. Attitudes roughly pertained to three topics. First, both support staff and relatives observed a number of possible reasons for people with intellectual disabilities to engage in sexual behavior. According to support staff, these reasons could include hormonal drives or searching for "motherly comfort" [42, p 42]. Both staff and relatives believed that people with intellectual disabilities engaged in sexual behavior to "relieve tension" [e.g., 63, p. 2180]. Furthermore, some support staff highlighted gender differences, with men perceived as searching for sexual gratification, while women sought an emotional connection [49]. However, other support staff and relatives expressed difficulties viewing the behavior of people with intellectual disabilities as sexually motivated, noting that the behavior was driven by (self) exploration or acts of friendship [42, 55, 58, 59].

Second, both support staff and relatives were quoted on their expectations of whether people with intellectual disabilities would actually express sexual behavior. Some relatives questioned if relationships would eventually turn out to be sexual in nature [53]. Similar to the attitudes expressed toward sexual needs, some support staff considered sexual behavior to be less likely if the person with an intellectual disability was a woman, of older age, and had a more severe intellectual disability [42, 60]. Conversely, several of the relatives in Meer and Combrinck [61] and Pownall et al. [53] studies believed that it was inevitable that people with intellectual disabilities would eventually become sexually active. Some support staff added, "at all levels of intelligence, sexual behavior is seen" [47, p 35].

Third, part of the identified attitudes reflected whether support staff and relatives accepted certain forms of sexual behavior. Generally speaking, both groups accepted autoerotic behavior (e.g., masturbation and watching pornography) [42, 43, 53, 60]. Although, for some support staff and relatives, certain forms of auto-erotic behavior were only acceptable if performed in the privacy of people's own bedroom [42, 43, 51]. Furthermore, Wilson and colleagues [42] indicated that for some support staff, masturbation was allowed as long the people with intellectual disabilities were even-tempered.

Contrary to auto-erotic behavior, support staff and relatives were more reserved toward forms of social-sexual behavior (e.g., cuddling, kissing, intercourse). Both support staff and relatives believed social-sexual behavior was acceptable "with discrete supervision" 
[45, p. 918]. Some support staff viewed cuddling as an appropriate intimate form of sexual behavior [42]. Conversely, some relatives stated people with intellectual disabilities should not touch anybody [64]. Sexual interaction (i.e., intercourse) was rejected by some support staff as well as relatives, based on concerns around mutual consent [43, support staff], sexually transmitted diseases, and/or unwanted pregnancies [62, relatives]. Moreover, within the spectrum of social-sexual behavior, some support staff dismissed same-sex sexual experiences more firmly as being inappropriate [49, 59], with some support staff believing that male-male sexual experiences originated from male-only residential groups [59]. Attitudes toward same-sex sexual experiences were not identified for relatives.

\section{Intimate Relationships of People with Intellectual Disabilities}

Attitudes toward intimate relationships of people with intellectual disabilities were found within eight studies based on the perspectives of support staff [43, 48, 49, 55, 59-61, 65], seven studies focused on relatives [44, 50-53, 62, 66], and one study addressing both groups [47]. Both support staff and relatives cited various reasons for why people with intellectual disabilities pursued intimate relations, namely: because they are supposed to; it is important; out of desire to kiss, hug, and/or engage in intercourse; and out of a desire to love and care for a partner [44, 48, 49, 52, 55]. Among both support staff and relatives, some shared the belief that relationships are frightening, and that the possibility of relationships provoked concerns around their vulnerability [43, 44, 46, 48, 49, 53, 65]. According to support staff, for men, this vulnerability primarily concerned the risk of becoming aggressive, whereas for women (unwanted) pregnancies was routinely emphasized [49]. Furthermore, in both Bates et al. [48] and Abott and Howarth's [55] studies, some support staff viewed people with intellectual disabilities as desperately seeking relationships, which led them to be open toward any gender, or accepting an abusive relationship. Some relatives believed that it was inevitable that intimate relationships would occur, with some believing that marriage and children were future possibilities [50, 53, 61, 66]. However, both support staff and relatives deemed that people with intellectual disabilities lacked the required social skills to establish and maintain relationships [43, 44, 48, 53]. This perceived lack of social skills led some support staff and relatives to conclude that marriage was simply not an option for people with intellectual disabilities [44, 47, 62].

\section{Theme Two: Attitudes toward Sex Education and Support}

The second theme consisted of four subthemes, which are explained in the following sections.

\section{The Forms of Sex Education and Support}

Support staff [ $n=4$ studies; 38, 41, 42, 43], relatives [ $n=4$ studies; 51, 52, 53, 67], and both groups $[n=3$ studies; 45, 46, 64] werequoted regarding their attitudes towards sex education and sexuality support. Several support staff and relatives viewed the provision of sex education as an important way to improve sexual health [46]. The support staff interviewed in Muswera and Kasiram's [38, p. 200] study mentioned that people with intellectual disabilities should "learn all the basics", although the authors doubted whether the staff knew exactly what this entailed. Indications for a more concrete interpretation of sex education were not found in this review. 
Besides sex education, both support staff and relatives recommended other suitable forms of support, namely: the provision of supervised private time, provision of medication to reduce sex drive, provision of contraception, and keeping the persons within the house/institution [41, 45, 51, 67]. Support staff and relatives believed that providing contraception protected people with intellectual disabilities from abuse and unwanted pregnancies $[41,51,53]$. For some support staff, providing contraception with consent was the preferred method, however doing so without their consent was also an option when the person with ID lacked the capacity to give it [41]. Furthermore, some relatives viewed contraception as a requirement for exploring their sexuality: "if you want to explore your sexuality, there is a choice to make and the choice is a vasectomy" [64, p. 606]. Other forms of sexuality-based support raised by support staff and relatives included: giving people with intellectual disabilities a choice over their sexual identity [55]; supporting sexual orientation and its' expression [59]; introducing assisted decision-making concerning their sexuality (i.e., supporting people with intellectual disabilities to attend meetings); and providing alternative means through which to express their sexuality [43]. These alternative means could include, among other things, providing them with pornographic materials. However, reported attitudes toward the provision of pornographic images were ambiguous, ranging from “... possibly a helpful aid" [42, p. 284, support staff] to a shared fear among support staff and relatives that watching pornography could have primarily negative consequences $[42,52]$.

\section{Reasons for Providing Sex Education and Support}

Several reported attitudes from support staff [ $n=6$ studies; 40, 42, 55, 56, 59, 60], relatives [ $n=3$ studies; 50, 51, 53], and both groups [ $n=2$ studies; 45, 46] pertained to the reasons for providing sex education and support to people with intellectual disabilities. There were differences between the participants, with some relatives opining that sex education should be provided at ".. any opportunity that there might be a link into" [53, p. 214], while one of the support staff mentioned that they should raise topics, such as sexual orientation, on a regular basis [59]. A recurring and widely shared attitude between the support staff and relatives was to introduce sex education when sexuality became problematic, in order to prevent abuse (either as a potential perpetrator or victim), and to prevent unwanted pregnancies [40, 42, 46, 53, 56]. However, other support staff and relatives suggested introducing it when the person with an ID raises the subject, or when they grew older, and/or sexual interest arises [42, 46, 53].

\section{Roles and Conditions for Providing Successful Sex Education and Support}

Some of the attitudes reported in two studies focused on support staff [40, 48], two studies on relatives $[52,53]$, and one addressing the perspectives of both [46], concerned what conditions are conducive to successful sex education provision and support. Support staff and relatives shared the belief that the sex education and support should match the educational needs of the people with intellectual disabilities. For instance, both mentioned that the sex education and support should be consistent and not too difficult [46], with relatives adding that it must be repeated regularly "... for it to sink in..." [53, p. 214]. Furthermore, relatives stressed that information should only be given when people with intellectual 
disabilities are mature enough to accept it, i.e. “... why give information to somebody if they're not ready to accept it basically?" [53, p. 215]. Regarding sexual support, some relatives expressed that they had a role in enabling their relative to have a sexual relationship [53]. Both support staff and relatives emphasized that people with intellectual disabilities also needed to be allowed to make mistakes $[46,48]$.

\section{Personal Barriers in the Provision of Sex Education and Support}

Attitudes of support staff and relatives toward personal barriers in the provision of sex education and support were reported in six studies focusing on support staff $[40,42,48,55$, $61,68]$, three studies focusing on relatives [53, 66, 67], and one focusing on both perspectives [46]. There was a commonly expressed tension among supporting staff and relatives regarding allowing and supporting sexual expression and relationships, while, simultaneously, keeping people with intellectual disabilities safe from sexual risks [48, 53]. As one of the support staff said, "because we are protecting her from the bad, we are also stopping her from the good" [48, p. 5]. In this vein, support staff and relatives conveyed insecurity over the provision of support and education, stressing that they needed more training, clearer guidelines, and permission from their management [40, 42, 46, 48, 53, 55, 67, 68]. For some support staff this insecurity led to a fear of accountability; "if they [the clients] came to me and asked me for help, I couldn't do it because my job and my neck would be on the line" [46, p. 35]. Other barriers cited by support staff pertained to certain institutionally imposed rules, such as those that prohibit intimate relations within the housing unit and prevent private chambers from being locked [40, 48]. Furthermore, some support staff doubted if staff with LGBT-identities were the best suited to support people with intellectual disabilities who also identified as LGBT [68]. From relatives' perspectives, the reported barriers leaned more towards either personal feelings of embarrassment or the expectation that their relatives with ID would get embarrassed when talking about sexuality $[46,53,61,66]$. As one relative noted: "I would find it very hard to talk about sexual intercourse or masturbation to him because I'm too close to him and he would be embarrassed and I would be embarrassed" [46, p. 35].

\section{Discussion}

The present systematic review aimed to provide an overview of extant literature on the attitudes of support staff and relatives toward the sexuality of people with intellectual disabilities. The attitudes identified pertained to two major themes, namely attitudes toward the sexuality of people with intellectual disabilities, and attitudes toward sex education and support. The subthemes encompassed a wide range of sexuality-related topics (e.g., sexual behavior, relationships, identity, sex education, sexuality support). Both supportive and restrictive attitudes were found across all the identified subthemes. Overall, the attitudes reported by both support staff and relatives appeared to be relatively similar in terms of being more or less supportive/restrictive. However, some indications were found of potential differences between the two groups. For instance, while both groups raised the risk of sexual abuse, for some support staff this risk was more associated with being held accountable for abuse [40, 46], while for some relatives this risk was primarily related to unwanted pregnancies and STIs $[53,64]$. Future research is thus needed to further elaborate on the 
attitudes of these groups. In light of the crucial role played by support staff and relatives in the provision of sex education and support [69], the authors have selected three implications that will be elaborated on below.

First, the attitudes of several support staff appeared to be more restrictive toward specific subgroups of people with intellectual disabilities [e.g., based on gender, age, severity of disability, and/or temper; 42, 49, 55, 58, 60]. This meant that it was difficult for those specific support staff to imagine that people with intellectual disabilities who belonged to one of these subgroups could have sexual needs. For instance, regarding people with severe intellectual disabilities or people with severe challenging behavior, some support staff simply labelled their behavior as forms of self-exploration or acts of friendship [e.g., 42, 55, 58], rather than an expression of sexual needs. These results appear to be in line with a review of stigma research, in which support staff were found to hold stronger restrictive attitudes toward the sexuality of people with severe intellectual disabilities and people with intellectual disabilities and challenging behavior [70]. Although their findings applied only to support staff, the same association may also apply to relatives. After all, both groups appeared to experience difficulties in assessing people with severe/profound intellectual disabilities' sexual needs [71]. Based on the present review, one can assume that the sexual needs of certain subgroups of people with intellectual disabilities are not yet recognized or are obfuscated because of attitudes that do not permit the existence of sexual needs. As sexuality is considered a basic aspect of being human, there is no reason to assume that this is any different for people with intellectual disabilities of any kind [4]. Therefore, it is recommended that both researchers and practitioners pay increased attention to the sexual needs of all subgroups of people with intellectual disabilities, alongside exploring the attitudes toward these subgroups from both support staff and relatives.

Second, the specificity of sexual behavior under consideration also appeared to influence the type of attitudes (i.e., supportive or restrictive) held by support staff and relatives. Similar to the attitudes of people with intellectual disabilities themselves [26], support staff and relatives appeared to be rather supportive toward sexuality in the broad sense of the term [i.e., 'sexuality in general'; 41, 43, 45]. However, attitudes could become increasingly restrictive, when more specific forms of behavior were considered [e.g., 'intercourse' or 'same-sex sexual experiences'; 43, 53, 59]. In some cases, such restrictive attitudes even resulted in actively discouraging people with intellectual disabilities from having sexual relations [e.g., 51, 64]. Some support staff viewed this as a "balancing act" between, on the one hand, offering freedom of sexual expression, and on the other, preventing harm through restriction [48]. The theory of reasoned action might provide an explanation for this acceptance of general concepts [e.g., "everybody has a right to sexuality"; 43, p. 143] while rejecting more concrete ideas [e.g., "we can't have people having ultimate relations; 43, p. 143]. This theory posits that a generally supportive set of attitudes toward general concepts might be altered into more restrictive attitudes when strong emotions get involved [72]. It is possible that strong emotions are provoked in support staff and relatives from the sexual risks perceived when considering the sexuality of people with intellectual disabilities. For example, such perceptions of sexual risk were sometimes associated with fear toward the sexuality of people with intellectual disabilities [7]. In the present review, both support staff and relatives framed these potential risks in terms of abuse, as either a perpetrator or a victim $[42,49,51,53,57]$. Several support staff expressed fear over being held accountable $[40,46]$, while unwanted pregnancies and sexually transmitted diseases were the prevailing fears among relatives [62]. Concern over sexual risk is decisive, insofar as it can lead to over-protection and the (unnecessary) limiting of sexual expression among people with intellectual disabilities [73, 74], viewing sexuality as a taboo subject [75]. In 
research on adolescent sexual development, there has been a notable shift away from risk prevention toward a focus on the normative development of sexuality $[9,11]$. This means that sexuality in and of itself is not considered a risk, but is rather viewed as part of the normative development through which young people learn to express sexuality, develop relations, and prevent sexual risk [10,11]. In future research and practice, it is thus recommended when developing methods that assess the perspectives of support staff and relatives toward sexual risk that they include a normative developmental perspective toward the sexuality or people with intellectual disabilities.

Finally, in the present review, restrictive and supportive attitudes were also reported concerning the provision of sex education and support. One notable finding is the lack of specific information regarding the suggested topics for sex education and support. For instance, only general descriptions like "having to learn the basics" [46], "constant supervision" [45], and "providing contraception" [e.g., 51] were routinely cited. The lack of more specific suggestions is striking, considering the finding that from the perception of people with intellectual disabilities themselves, a considerable number of suggestions were reported. These pertained to intimacy, love, dating, relationships, sexual pleasure, and avoiding risks [26]. The lack of data on specific topics may represent a barrier for support staff and relatives in the provision of support and education [8,30], due to feelings of insecurity [40, 42]. The insecurity voiced by support staff was associated with institutionally imposed rules and a lack of managerial support [40, 48]. For relatives, this insecurity is perhaps related to embarrassment, which, in turn, could lead them to neglect the needs, views, and attitudes of people with intellectual disabilities in their sex education and support $[46,53,61,66]$. Significantly, support staff, relatives, and people with intellectual disabilities [26] stressed that it was important that sex education and support matches the educational needs of people with intellectual disabilities. For this to occur, several of the support needs cited by staff and relatives themselves in the present review must be addressed, including receiving staff training, having clear guidelines, and receiving support from management [e.g., 40, 42, 46, 67]. Future research and practice could further develop methods that allow support staff and relatives to include the attitudes of people with intellectual disabilities in the provided sex education and support. Furthermore, future research could also explore the attitudes of support staff and relatives toward sex education and support, in turn, allowing for the development of much needed support training and guidelines.

The present systematic review has its limitations. Given that it is a review of qualitative data, only an assessment of the differences between the attitudes of support staff and relatives could be explored. For instance, it appears that support staff held more reservations toward the sexuality of certain subgroups, while for relatives the sexual behavior in itself was more decisive. These findings may give rise to future quantitative research that would be better suited to determine any differences between support staff and relatives with a greater degree of certainty. Future quantitative research could also assess the predictive value of attitudes on the quality of sex education and support provided. In so doing, future quantitative research could thus contribute to a better understanding of the role that the attitudes of support staff and relatives have upon the sexual health promotion of people with intellectual disabilities. Lastly, due to the inclusion and exclusion criteria, results on sex education and support only pertained to adults with intellectual disabilities. This limitation is relevant in light of the conclusions from Brown et al. [69], according to which the majority of education developed for people with intellectual disabilities is targeted toward children and youths.

In conclusion, the present review provides some insights into both the supportive and restrictive attitudes held by support staff and relatives toward the sexuality of people with 
intellectual disabilities. Despite holding generally accepting view toward sexual rights and sexuality in general, some support staff and relatives approached more concrete forms of sexuality with greater reservation. In addition, the sexual needs of certain subgroups are possibly obfuscated. Moreover, support staff and relatives who express rather restrictive attitudes are potentially over-emphasizing the sexual risks to people with intellectual disabilities. Finally, while the attitudes underlined the importance of sex education and support for people with intellectual disabilities, for some support staff and relatives the provision of sex education and support was nevertheless associated with feelings of insecurity. This review has put forward some recommendations on how to further develop the training and support for support staff and relatives in order to allow for the promotion of sexual health among people with intellectual disabilities.

Authors' contributions All authors contributed to the study conception and design of the present review. The search strategy and its update of the search were conducted with the support of WB and EK from the Erasmus MC Medical Library. Screening of the articles commenced with the support from MT and SN from Tranzo, Tilburg School of Social and Behavioral Sciences, Tilburg University. All authors contributed on the datasynthesis. The first draft of the manuscript was written by WW and all authors commented on previous versions of the manuscript. All authors read and approved the final manuscript.

Funding The present review was funded by the Zorgondersteuningsfonds, a not-for profit funding agency.

Data Availability (Secondary) data and materials used in this research are available.

\section{Declarations}

Conflict of interest The authors have no conflicts of interest to declare that are relevant to the content of this article.

Consent for Publication Consent for publication has been received by all authors.

Open Access This article is licensed under a Creative Commons Attribution 4.0 International License, which permits use, sharing, adaptation, distribution and reproduction in any medium or format, as long as you give appropriate credit to the original author(s) and the source, provide a link to the Creative Commons licence, and indicate if changes were made. The images or other third party material in this article are included in the article's Creative Commons licence, unless indicated otherwise in a credit line to the material. If material is not included in the article's Creative Commons licence and your intended use is not permitted by statutory regulation or exceeds the permitted use, you will need to obtain permission directly from the copyright holder. To view a copy of this licence, visit http://creativecommons.org/licenses/by/4.0/.

\section{References}

1. Ailey, S.H., Marks, B.A., Crisp, C., Hahn, J.E.: Promoting sexuality across the life span for individuals with intellectual and developmental disabilities. Nurs. Clin. North Am. 38(2), 229-252 (2003). https:// doi.org/10.1016/S0029-6465(02)00056-7

2. Servais, L.: Sexual health care in persons with intellectual disabilities. Ment. Retard. Dev. Disabil. Res. Rev. 12, 48-56 (2006). https://doi.org/10.1002/mrdd.20093

3. Aunos, M., Feldman, M.A.: Attitudes towards sexuality, sterilization and parenting rights of persons with intellectual disabilities. J. Appl. Res. Intellect 15(4), 285-296 (2002). https://doi.org/10.1046/j. 1468-3148.2002.00135.x 
4. World Association for Sexual Health: Working Definitions after WHO Technical Consultation on Sexual Health. https://worldsexualhealth.net/wp-content/uploads/2013/08/working-definitions-after-who. pdf (2014) Accessed 6 March 2020

5. English, B., Tickle, A., das Nair, R., Moore, K.: Consensus-based good practice guidelines for clinical psychologists to support care staff in enabling sexual expression in people with intellectual disabilities: a Delphi study. J. Appl. Res. Intellect. 33(2), 268-282 (2020). https://doi.org/10.1111/jar.12671

6. McCarthy, M.: Women with intellectual disability: their sexual lives in the 21 st century. J. Intellect. Dev. Disabil. 39(2), 124-131 (2014). https://doi.org/10.3109/13668250.2014.894963

7. Rushbrooke, E., Murray, C., Townsend, S.: The experiences of intimate relationships by people with intellectual disabilities: a qualitative study. J. Appl. Res. Intellect. 27(6), 531-541 (2014). https://doi. org/10.1111/jar.12091

8. Stoffelen, J.M.T., Herps, M.A., Buntinx, W.H.E., Schaafsma, D., Kok, G., Curfs, L.M.G.: Sexuality and individual support plans for people with intellectual disabilities. J. Intellect. Disabil. Res. 61(12), 1117-1129 (2017). https://doi.org/10.1111/jir.12428

9. van de Bongardt, D., Yu, R., Deković, M., Meeus, W.H.J.: Romantic relationships and sexuality in adolescence and young adulthood: the role of parents, peers, and partners. Eur. J. Dev. Psychol. 12(5), 497-515 (2015). https://doi.org/10.1080/17405629.2015.1068689

10. Collins, W.A., Welsh, D.P., Furman, W.: Adolescent romantic relationships. Annu. Rev. Psychol. 60, 631-652 (2009). https://doi.org/10.1146/annurev.psych.60.110707.163459

11. Tolman, D.L., McClelland, S.I.: Normative sexuality development in adolescence: a decade in review, 2000-2009. J. Res. Adolesc. 21(1), 242-255 (2011). https://doi.org/10.1111/j.1532-7795.2010. 00726.x

12. World Health Organization: Sexual Health, Human Rights and the Law. WHO Press, Geneva (2015)

13. Brown, M., McCann, E.: Sexuality issues and the voices of adults with intellectual disabilities: a systematic review of the literature. Res. Dev. Disabil. 74, 124-138 (2018). https://doi.org/10.1016/j.ridd. 2018.01.009

14. Brown, R.D., Pirtle, T.: Beliefs of professional and family caregivers about the sexuality of individuals with intellectual disabilities: examining beliefs using a Q-methodology approach. Sex Educ. 8(1), 59-75 (2008). https://doi.org/10.1080/14681810701811829

15. Cuskelly, M., Bryde, R.: Attitudes towards the sexuality of adults with an intellectual disability: parents, support staff, and a community sample. J. Intellect. Dev. Disabil. 29(3), 255-264 (2004). https:// doi.org/10.1080/13668250412331285136

16. Kersten, M.C.O., Taminiau-Bloem, E.F., Schuurman, M., Weggeman, M.C.D.P., Embregts, P.J.C.M.: How to improve sharing and application of knowledge in care and support for people with intellectual disabilities? A systematic review. J. Intellect. Disabil. Res. 62(6), 496-520 (2018). https://doi.org/10. $1111 /$ jir.12491

17. Wilkinson, V.J., Theodore, K., Raczka, R.: 'As normal as possible': Sexual identity development in people with intellectual disabilities transitioning to adulthood. Sex. Disabil. 33(1), 93-105 (2015). https://doi.org/10.1007/s11195-014-9356-6

18. Wilson, M.C., Scior, K.: Implicit attitudes towards people with intellectual disabilities: their relationship with explicit attitudes, social distance, emotions and contact. PLoS ONE 10(9), e0137902 (2015). https://doi.org/10.1371/journal.pone.0137902

19. Gougeon, N.A.: Sexuality education for students with intellectual disabilities, a critical pedagogical approach: outing the ignored curriculum. Sex Educ 9(3), 277-291 (2009). https://doi.org/10.1080/ 14681810903059094

20. Medina-Rico, M., López-Ramos, H., Quiñonez, A.: Sexuality in people with intellectual disability: review of literature. Sex. Disabil. 36(3), 231-248 (2018). https://doi.org/10.1007/s11195-017-9508-6

21. Whittle, C., Butler, C.: Sexuality in the lives of people with intellectual disabilities: a meta-ethnographic synthesis of qualitative studies. Res. Dev. Disabil. 75, 68-81 (2018). https://doi.org/10.1016/j. ridd.2018.02.008

22. Ford, J.V., Vargas, E.C., Finotelli, I., Jr., Fortenberry, J.D., Kismödi, E., Philpott, A., Rubio-Aurioles, E., Coleman, E.: Why pleasure matters: Its global relevance for sexual health, sexual rights and wellbeing. Int. J. Sex. Health 31(3), 217-230 (2019). https://doi.org/10.1080/19317611.2019.1654587

23. Carlson, G., Taylor, M., Wilson, J.: Sterilisation, drugs which suppress sexual drive, and young men who have intellectual disability. J. Intellect. Dev. Disabil. 25(2), 91-104 (2000). https://doi.org/10. $1080 / 13269780050033517$

24. Schaafsma, D., Kok, G., Stoffelen, J.M.T., Curfs, L.M.G.: Identifying effective methods for teaching sex education to individuals with intellectual disabilities: a systematic review. J. Sex Res. 52(4), 412432 (2015). https://doi.org/10.1080/00224499.2014.919373 
25. Travers, J., Tincani, M., Whitby, P.S., Boutot, E.A.: Alignment of sexuality education with self determination for people with significant disabilities: a review of research and future directions. Educ. Train. Autism Dev. Disabil 49(2), 232-247 (2014)

26. De Wit, W., Van Oorsouw, W.M.J.W., Embregts, P.J.C.M.: Attitudes towards sexuality and related caregiver support of people with intellectual disabilities: a systematic review on the perspectives of people with intellectual disabilities. J. Appl. Res. Intellect. Disabil. 35(1), 75-87 (2021). https://doi.org/ 10.1111/jar.12928

27. Boislard, M.A., Van de Bongardt, D., Blais, M.: Sexuality (and lack thereof) in adolescence and early adulthood: a review of the literature. Behav. Sci. 6(1), 8 (2016). https://doi.org/10.3390/bs6010008

28. Cox, R.B., Jr., Shreffler, K.M., Merten, M.J., Schwerdtfeger Gallus, K.L., Dowdy, J.L.: Parenting, peers, and perceived norms: what predicts attitudes toward sex among early adolescents? J. Early Adolesc. 35(1), 30-53 (2015). https://doi.org/10.1177/2F0272431614523131

29. Overbeek, G., van de Bongardt, D., Baams, L.: Buffer or brake? The role of sexuality-specific parenting in adolescents' sexualized media consumption and sexual development. J. Youth Adolesc. 47(7), 1427-1439 (2018). https://doi.org/10.1007/s10964-018-0828-3

30. Brown, M., McCann, E.: The views and experiences of families and direct care support workers regarding the expression of sexuality by adults with intellectual disabilities: a narrative review of the international research evidence. Res. Dev. Disabil. 90, 80-91 (2019). https://doi.org/10.1016/j.ridd. 2019.04.012

31. Chrastina, J., Večeřová, H.: Supporting sexuality in adults with intellectual disability: a short review. Sex. Disabil. 38(2), 285-298 (2020). https://doi.org/10.1007/s11195-018-9546-8

32. Liberati, A., Altman, D.G., Tetzlaff, J., Mulrow, C., Gøtzche, P.C., Ioannidis, J.P.A., Clarke, M., Devereaux, P.J., Kleijnen, J., Moher, D.: The PRISMA statement for reporting systematic reviews and meta-analysis of studies that evaluate healthcare interventions: explanation and elaboration. J. Clin. Epidemiol. 65(10), e1-e34 (2009). https://doi.org/10.1016/j.jclinepi.2009.06.006

33. Bramer, W.M., de Jonge, G.B., Rethlefsen, M.L., Mast, F., Kleijnen, J.: A systematic approach to searching: an efficient and complete method to develop literature searches. J. Med. Libr. Assoc. 106(4), 531-541 (2018). https://doi.org/10.5195/jmla.2018.283

34. Prislin, R., Crano, W.D.: Attitudes and attitude change: the fourth peak. In: Prislin, R., Crano, W.D. (eds.) Attitudes and Attitude Change, pp. 3-15. Taylor \& Francis Group, Abingdon (2008)

35. Moher, D., Liberati, A., Tetzlaff, J., Altman, D.G., The PRISMA Group: Preferred reporting items for systematic reviews and meta-analyses: the PRISMA Statement. PLOS Med. 6(7), 1-6 (2009). https:// doi.org/10.1371/journal.pmed.1000097

36. Hong, Q. N., Pluye, P., Fàbregues, S., Bartlett, G., Boardman, F., Cargo, M., Dagenais, P., Gagnon, M.-P., Griffiths, F., Nicolau, B., O'Cathain, A., Rousseau, M.-C., \& Vedel, I.: Mixed Methods Appraisal Tool (MMAT), version 2018. I. C. Canadian Intellectual Property Office (2018)

37. Lachal, J., Revah-Levy, A., Orri, M., Moro, M.R.: Metasynthesis: an original method to synthesize qualitative literature in psychiatry. Front. Psychiatr. 8, 269-278 (2017). https://doi.org/10.3389/fpsyt. 2017.00269

38. Muswera, T., Kasiram, M.: Understanding the sexuality of persons with intellectual disability in residential facilities: perceptions of service providers and people with disabilities. Soc. Work 55(2), 196204 (2019). https://doi.org/10.15270/52-2-715

39. Oakes, L.R., Thorpe, S.: The sexual health needs and perspectives of college students with intellectual and/or developmental disabilities and their support staff: a brief report. Sex. Disabil. 37(4), 587-598 (2019). https://doi.org/10.1007/s11195-019-09602-6

40. Pariseau-Legault, P., Holmes, D., Ouellet, G., Vallée-Ouimet, S.: An ethical inquiry of support workers' experiences related to sexuality in the context of intellectual disabilities in Quebec Canada. Br. J. Learn. Disabil. 47(2), 116-125 (2019). https://doi.org/10.1111/bld.12264

41. Parley, F.: The understanding that care staff bring to abuse. J. Adult Prot. 12(1), 13-26 (2010). https:// doi.org/10.5042/jap.2010.0090

42. Wilson, N.J., Parmenter, T.R., Stancliffe, R.J., Shuttleworth, R.P.: Conditionally sexual: men and teenage boys with moderate to profound intellectual disability. Sex. Disabil. 29(3), 275-289 (2011). https:// doi.org/10.1007/s11195-011-9203-y

43. Yool, L., Langdon, P.E., Garner, K.: The attitudes of medium-secure unit staff toward the sexuality of adults with learning disabilities. Sex. Disabil. 21(2), 137-150 (2003). https://doi.org/10.1023/A:10254 99417787

44. Neuman, R.: Parents' perceptions regarding couple relationships of their adult children with intellectual disabilities. J. Appl. Res. Intellect. Disabil. 33(2), 310-320 (2020). https://doi.org/10.1111/jar. 12674 
45. Evans, D.S., McGuire, B.E., Healy, E., Carley, S.N.: Sexuality and personal relationships for people with an intellectual disability. Part II: staff and family carer perspectives. J. Appl. Res. Intellect. Disabil. 53(11), 913-921 (2009). https://doi.org/10.1111/j.1365-2788.2009.01202.X

46. Lafferty, A., McConkey, R., Simpson, A.: Reducing the barriers to relationships and sexuality education for persons with intellectual disabilities. J. Intellect. Disabil. 16(1), 29-43 (2012). https://doi.org/ 10.1177/2F1744629512438034

47. Taghizadeh, Z., Ebadi, A., Farahani, M.F.: Marriage challenges of women with intellectual disability in Iran: a qualitative study. Sex. Disabil. 38(1), 31-39 (2020). https://doi.org/10.1007/ s11195-019-09615-1

48. Bates, C., McCarthy, M., Milne Skillman, K., Elson, N., Forrester-Jones, R., Hunt, S.: “Always trying to walk a bit of a tightrope": the role of social care staff in supporting adults with intellectual and developmental disabilities to develop and maintain loving relationships. Br. J. Learn. Disabil. 48(4), 261-268 (2020). https://doi.org/10.1111/bld.12320

49. Young, R., Gore, N., McCarthy, M.: Staff attitudes towards sexuality in relation to gender of people with intellectual disability: a qualitative study. J. Intellect. Dev. Disabil. 37(4), 343-347 (2012). https:// doi.org/10.3109/13668250.2012.704983

50. Goodwin, J., Swaab, L., Campbell, L.E.: She'll be able to live independently... as long as I'm around": the "lived" experience of parenting a child with 22q11.2 deletion syndrome in the transition to adulthood. J. Appl. Res. Intellect. Disabil. 33(3), 565-573 (2020). https://doi.org/10.1111/jar.12700

51. Kahonde, C.K., McKenzie, J., Wilson, N.J.: Discourse of needs versus discourse of rights: family caregivers responding to the sexuality of young South African adults with intellectual disability. Cult. Health Sex. 21(3), 278-292 (2019). https://doi.org/10.1080/13691058.2018.1465202

52. Löfgren-Mårtenson, L., Sorbring, E., Molin, M.: “T@ ngled up in blue”: Views of parents and professionals on internet use for sexual purposes among young people with intellectual disabilities. Sex. Disabil. 33(4), 533-544 (2015). https://doi.org/10.1007/s11195-015-9415-7

53. Pownall, J.D., Jahoda, A., Hastings, R., Kerr, L.: Sexual understanding and development of young people with intellectual disabilities: mothers' perspectives of within-family context. Am. J. Intellect. Dev. Disabil. 116(3), 205-219 (2011). https://doi.org/10.1352/1944-7558-116.3.205

54. Callus, A.M., Bonello, I., Mifsud, C., Fenech, R.: Overprotection in the lives of people with intellectual disability in Malta: knowing what is control and what is enabling support. Disabil. Soc. 34(3), 345-367 (2019). https://doi.org/10.1080/09687599.2018.1547186

55. Abbott, D., Howarth, J.: Still off-limits? Staff views on supporting gay, lesbian and bisexual people with intellectual disabilities to develop sexual and intimate relationships. J. Appl. Res. Intellect. Disabil 20(2), 116-126 (2007). https://doi.org/10.1111/j.1468-3148.2006.00312.x

56. Broughton, S., Thomson, K.: Women with learning disabilities: risk behaviours and experiences of the cervical smear test. J. Adv. Nurs. 32(4), 905-912 (2000). https://doi.org/10.1046/j.1365-2648. 2000.t01-1-01555.x

57. Clegg, J., Sheard, C., Cahill, J., Osbeck, L.: Severe intellectual disability and transition to adulthood. Br. J. Clin. Psychol. 74(2), 151-166 (2001). https://doi.org/10.1348/000711201160885

58. Löfgren-Mårtenson, L.: The invisibility of young homosexual women and men with intellectual disabilities. Sex. Disabil. 27(1), 21-26 (2009). https://doi.org/10.1007/s11195-008-9101-0

59. Dudek, S., Jeschke, K., \& Lehmkuhl, U.: Homosexuality in residential facilities for people with cognitive disabilities. Disabil. Stud. Q. 26(2) (2006)

60. Maguire, K., Gleeson, K., Holmes, N.: Support workers' understanding of their role supporting the sexuality of people with learning disabilities. Br. J. Learn. Disabil. 47(1), 59-65 (2019). https://doi. org/10.1111/bld.12256

61. Meer, T., Combrinck, H.: Invisible intersections: understanding the complex stigmatisation of women with intellectual disabilities in their vulnerability to gender-based violence. Agenda 29(2), 14-23 (2015). https://doi.org/10.1080/10130950.2015.1039307

62. Kahonde, C.K., McKenzie, J., Wilson, N.J.: The impact of lifelong family care on family caregivers' perceptions of the sexuality of young adults with intellectual disabilities in the western cape of South Africa. Sex. Disabil. 38(1), 95-105 (2020). https://doi.org/10.1007/s11195-019-09595-2

63. Van Remmerden, M.C., Hoogland, L., Mous, S.E., Dierckx, B., Coesmans, M., Moll, H.A., Van Eeghen, A.M.: Growing up with fragile X syndrome: concerns and care needs of young adult patients and their parents. J. Autism Dev. Disord. 50(6), 2174-2187 (2020). https://doi.org/10. 1007/s10803-019-03973-7

64. Pariseau-Legault, P., Holmes, D.: Mediated pathways, negotiated identities: a critical phenomenological analysis of the experience of sexuality in the context of intellectual disability. J. Res. Nurs. 22(8), 599-614 (2017). https://doi.org/10.1177/2F1744987117735363 
65. Löfgren-Mårtenson, L.: Love in cyberspace: Swedish young people with intellectual disabilities and the Internet. Scand. J. Disabil. Res. 10(2), 125-138 (2008). https://doi.org/10.1080/15017 410701758005

66. Hepper, F.: 'A woman's heaven is at her husband's feet'1? The dilemmas for a community learning disability team posed by the arranged marriage of a Bangladeshi client with intellectual disability. J. Intellect. Disabil. Res. 43(6), 558-561 (1999). https://doi.org/10.1046/j.1365-2788.1999.00226.x

67. Biswas, S., Tickle, A., Golijani-Moghaddam, N., Almack, K.: The transition into adulthood for children with a severe intellectual disability: parents' views. Int. J. Dev. Disabil. 63(2), 99-109 (2017). https://doi.org/10.1080/20473869.2016.1138598

68. Abbott, D., Burns, J.: What's love got to do with it?: Experiences of lesbian, gay, and bisexual people with intellectual disabilities in the United Kingdom and views of the staff who support them. Sex Res. Soc. Policy 4(1), 27-39 (2007). https://doi.org/10.1525/srsp.2007.4.1.27

69. Brown, M., McCann, E., Truesdale, M., Linden, M., Marsh, L.: The design, content and delivery of relationship and sexuality education programmes for people with intellectual disabilities: a systematic review of the international evidence. Int. J. Environ. Res. 17(20), 7568 (2020). https://doi.org/ 10.3390/ijerph17207568

70. Pelleboer-Gunnink, H.A., van Oorsouw, W.M., van Weeghel, J., Embregts, P.J.: Stigma research in the field of intellectual disabilities: a scoping review on the perspective of care providers. Int. J. Dev. Disabil. (2019). https://doi.org/10.1080/20473869.2019.1616990

71. De Geus-Neelen, K.C., van Oorsouw, W.M., Hendriks, L.A., Embregts, P.J.: Perceptions of staff and family of the quality of life of people with severe to profound intellectual disability. J. Intellect. Dev. Disabil. 44(1), 42-50 (2019). https://doi.org/10.3109/13668250.2017.1310813

72. Ajzen, I., Fishbein, M.: The influence of attitudes on behavior. In: Albarracín, D., Johnson, B.T., Zanna, M.P. (eds.) The Handbook of Attitudes, pp. 173-221. Lawrence Erlbaum Associates Publishers, Mahwah (2005)

73. McCann, E., Marsh, L., Brown, M.: People with intellectual disabilities, relationship and sex education programmes: a systematic review. Health Educ. J. 78(8), 885-900 (2019). https://doi.org/10.1177/ 2F0017896919856047

74. Pelleboer-gunnink, H.A., Van Oorsouw, W.M.W.J., Van Weeghel, J., Embregts, P.J.C.M.: Mainstream health professionals' stigmatising attitudes towards people with intellectual disabilities: a systematic review. J. Intellect. Disabil. Res. 61(5), 411-434 (2017). https://doi.org/10.1111/jir.12353

75. Dionne, H., Dupras, A.: Sexual health of people with an intellectual disability: an ecosystem approach. Sexologies 23(4), e85-e89 (2014). https://doi.org/10.1016/j.sexol.2013.12.004

Publisher's Note Springer Nature remains neutral with regard to jurisdictional claims in published maps and institutional affiliations. 